BMJ Open Sport \& Exercise Medicine

\title{
Update on the effects of physical activity on insulin sensitivity in humans
}

\author{
Stephen R Bird, ${ }^{1}$ John A Hawley ${ }^{2,3}$
}

To cite: Bird SR, Hawley JA. Update on the effects of physical activity on insulin sensitivity in humans. BMJ Open Sport Exerc Med 2017;2:e000143 doi:10.1136/bmjsem-2016000143

- Prepublication history and additional material is available. To view please visit the journal (http://dx.doi.org/ 10.1136/bmjsem-2016000143).

Accepted 28 December 2016

\section{CrossMark}

\section{${ }^{1}$ School of Health and Biomedical Sciences, RMIT University, Melbourne, Victoria, Australia ${ }^{2}$ Mary MaKillop Institute for Health Research, Centre for Exercise and Nutrition, Australian Catholic University, Melbourne, Victoria, Australia ${ }^{3}$ Research Institute for Sport and Exercise Sciences, Liverpool John Moores University, Liverpool, UK}

Correspondence to Professor Stephen R Bird; Stephen.bird@rmit.edu.au

\section{ABSTRACT}

Purpose and methods: This review presents established knowledge on the effects of physical activity (PA) on whole-body insulin sensitivity (SI) and summarises the findings of recent (2013-2016) studies.

Discussion and conclusions: Recent studies provide further evidence to support the notion that regular PA reduces the risk of insulin resistance, metabolic syndrome and type 2 diabetes, and $\mathrm{SI}$ improves when individuals comply with exercise and/or PA guidelines. Many studies indicate a dose response, with higher energy expenditures and higher exercise intensities, including high intensity interval training (HIIT), producing greater benefits on whole-body SI, although these findings are not unanimous. Aerobic exercise interventions can improve SI without an associated increase in cardiorespiratory fitness as measured by maximal or peak oxygen consumption. Both aerobic and resistance exercise can induce improvements in glycaemic regulation, with some suggestions that exercise regimens including both may be more efficacious than either exercise mode alone. Some studies report exercise-induced benefits to SI that are independent of habitual diet and weight loss, while others indicate an association with fat reduction, hence the debate over the relative importance of PA and weight loss continues. During exercise, muscle contraction stimulated improvements in SI are associated with increases in AMPK activity, which deactivates TCB1D1, promoting GLUT4 translocation to the cell membrane and thereby increasing glucose uptake. Postexercise, increases in Akt deactivate TCB1D4 and thereby increase GLUT4 translocation to the cell membrane. The reduction in intramuscular saturated fatty acids and concomitant reductions in ceramides, but not diacylglycerols, provide a potential link between intramuscular lipid content and SI. Increased skeletal muscle capillarisation provides another independent adaptation through which $\mathrm{SI}$ is improved, as does enhanced $\beta$ cell activity. Recent studies are combining exercise interventions with dietary and feeding manipulations to investigate the potential for augmenting the exercise-induced improvements in SI and glycaemic control.

\section{INTRODUCTION}

Individuals with poor insulin sensitivity (SI) are characterised by impaired insulin action on whole-body glucose uptake. This results in elevated blood (glucose), impaired glycaemic control, a risk of pancreatic $\beta$ cell failure and the development of type 2 diabetes (T2D). In developed countries the prevalence of this prediabetic state is currently reported to be $15-20 \% .^{1}$ Furthermore, it is estimated that 366 million people, $\sim 8 \%$ of the population are affected by diabetes worldwide, ${ }^{2}$ hence strategies for the treatment of the prediabetic state, its prevention and preventing progression from prediabetes to T2D are an imperative. Key among these is the inclusion of physical activity (PA) into a healthy lifestyle, and current research in this field continues to seek to understand the behavioural and molecular aspects of exercise in preventing diabetes and poor SI, with the intent to identify efficacious exercise interventions.

The comparison of results between research studies into the effects of a physically active lifestyle and/or exercise on insulin sensitivity and glycaemic control are problematic due to differences in the methods of assessment of outcome variables. While the precise protocols vary, the general methods for assessing insulin sensitivity/glycaemic control include: (1) measuring fasting insulin concentrations, with elevated fasted (insulin) $>25 \mathrm{mIU} / \mathrm{L}$ indicating poor insulin sensitivity, as the pancreas endeavours to compensate for the lack of peripheral insulin sensitivity by secreting greater amounts of insulin, thereby resulting in hyperinsulinaemia; (2) oral glucose tolerance testing (OGTT), which involves the ingestion of a standard glucose bolus $(75 \mathrm{~g})$, followed by blood glucose monitoring for the subsequent 2 hours. Blood glucose concentrations of $>7.8 \mathrm{mmol} / \mathrm{L}$ and $<11.0 \mathrm{mmol} / \mathrm{L}$ at 2 hours are indicative of impaired glycaemic control, and $>11.0 \mathrm{mmol} / \mathrm{L}$ indicates diabetes; (3) hyperinsulinaemic-euglycaemic clamp, in which the participant is infused with insulin at a known rate, creating a hyperinsulinaemic state $(\sim 100 \mu \mathrm{U} / \mathrm{ml})$, while simultaneously blood glucose levels are 


\section{Key messages}

\section{What are the new findings?}

In addition to adding further support to the established position that a lifestyle that includes regular physical activity (PA) is associated with a good insulin sensitivity $(\mathrm{SI})$ and exercise interventions can improve $\mathrm{SI}$, evidence is growing for the following key findings:

- Aerobic exercise may increase SI without a measurable increase in $\mathrm{VO}_{2}$ max or $\mathrm{VO}_{2}$ peak

- A dose effect may be evident, with greater exercise volumes and higher exercise intensities, including high intensity interval training (HIIT) or sprint interval training (SIT), producing greater benefits to SI.

- The combination of aerobic exercise training and REX may be more effective than either exercise mode alone.

- Exercise induced benefits may be augmented by appropriate dietary and feeding manipulations.

- Molecular research has identified key signalling molecules and proteins that are influenced by exercise and provide the link to resultant changes in $\mathrm{SI}$.

- Evidence is accumulating for ceramides to be the causal link between obesity and a reduced SI.

\section{Practical recommendations}

- Despite the aforementioned general consensus, not all findings are consistent, and the specific details of the most efficacious forms of exercise/physical activity (PA) for improving or maintaining insulin sensitivity $(\mathrm{SI})$ require further elucidation in order for exercise prescription to be optimised.

- Research needs to assess the interaction of dietary/feeding manipulations and exercise on SI and glycaemic control, as these may augment the beneficial outcomes of the interventions.

- Future research needs to consider the potential influence of exercise induced improvements to $\beta$ cell function and increased muscle capillarisation, alongside the contribution of intramuscular changes that result in improved SI, GLUT4 availability and glycaemic control.

- Studies will also need to consider potential differences in the adaptations induced by different exercise modalities, aerobic versus REX; exercise intensities and volumes, including interval training (high intensity interval training (HIIT) and sprint interval training (SIT)); and differences in the adaptations of different fibre types.

- Likewise, the potential to adapt and improve SI is likely to be influenced by the basal state of the participants: with healthy participants, overweight/obese, prediabetic metabolic syndrome, and patients with diabetes all likely to differ in the magnitude of adaptation and improvement.

- Given the evident benefits of PA/exercise interventions for preventing diabetes, even among those with metabolic risk factors, studies aimed at identifying effective preventive strategies are paramount in order to prevent further increases in the prevalence of type 2 diabetes, particularly since only $10 \%$ of current clinical trials focus on prevention and only $\sim 12 \%$ use behavioural interventions such as PA rather than drugs, which are the focus of $\sim 63.1 \%$ of studies. ${ }^{101}$ monitored and adjusted by a variable-rate infusion to maintain glycaemia $(5.0-5.5 \mathrm{mmol} / \mathrm{L})$. A high rate of glucose infusion indicates insulin sensitivity as the glucose is being rapidly taken up by the cells of the body, while a low rate of glucose infusion indicates a loss of insulin sensitivity, as the glucose is remaining in the blood rather than being taken up by the cells of the body; ${ }^{3}$ (4) hyperglycaemic clamp, in which plasma glucose levels are initially increased to $\sim 125 \mathrm{mg} / \mathrm{dl}$ above basal values and then maintained at this hyperglycaemic level, through the infusion of glucose. High infusion rates indicate good insulin sensitivity, while low infusion rates indicate insulin resistance (IR). ${ }^{3} ;(5)$ homoeostatic model assessment of insulin resistance (HOMA-IR), which uses fasting (glucose) and insulin, and is calculated as (glucose $\mathrm{mmol} / \mathrm{L} \mathrm{x}$ insulin)/22.5, with a relatively low score indicating well regulated fasting glucose that is being maintained through relatively low concentrations of insulin, hence good insulin sensitivity, whereas an elevated HOMA-IR value, such as $>2.5$ indicates IR. In the updated homoeostatic model, HOMA2-IR, values $>1.5$ suggest IR; (6) HOMA- $\beta$ is a measure of $\beta$ cell function derived from fasting values using the equation $(20 \mathrm{x}$ insulin)/(glucose $\mathrm{mmol} / \mathrm{L}-3.5) \%$, with this measure indicating the extent to which a deficient $\beta$ cell function, as opposed to IR, contributes to hyperglycaemia in the fasting state; (7) Quantitative Insulin Sensitivity Check Index (QUICKI), which is an index of insulin sensitivity, calculated as QUICKI $=1 /(\log$ (fasting plasma insulin $\mu \mathrm{U} / \mathrm{ml})+\log ($ fasting blood glucose $\mathrm{mg} / \mathrm{dL}))^{4}$

Regardless of the methods used to assess insulin sensitivity/glycaemic control, a lifestyle incorporating regular PA has been identified as a key factor for maintaining and improving many aspects of health, including insulin sensitivity. ${ }^{5}{ }^{6}$ In this context, the term PA covers all forms of muscular movement, including that associated with strenuous physical work, active transport (walking and cycling), household tasks (cleaning and gardening), incidental PA which occurs when undertaking other tasks, sport and other active leisure pursuits. Whereas the term 'exercise' refers specifically to the context of PA that is undertaken with the specific intent of improving health and/or fitness and is therefore a subset of PA. Hence many crosssectional studies investigate PA levels as well as specific exercise habits, but interventions tend to involve exercise, as they have the specific intent of affecting an aspect of health.

Cross-sectional studies identify an association between regular PA and/or aerobic fitness and superior SI. ${ }^{5} 6$ Adding further support to this association, studies involving exercise interventions usually report an amelioration or in some cases, complete reversal of IR. ${ }^{78}$ Assessments of the impact of a physically active lifestyle suggest a dose response with each $500 \mathrm{kcal} /$ week increase in PA, reducing the risk of T2D by $\sim 9 \% .^{9}$ 
Physical activity has both immediate (acute) and longer-term effects on insulin sensitivity. The immediate effects are the direct result of a single exercise bout and may be evident during and/or for up to 72 hours postexercise. If repeated regularly these bouts produce additional long-term chronic improvements to SI, thereby providing superior baseline glycaemic control compared with that typically seen in less active individuals. In this healthy, physically active, 'trained' condition, the effects of individual exercise bouts may then produce further acute responses from this already elevated SI state and thereby promote optimal SI and glycaemic control. Some key issues around PA that are considered in recent literature include: the effects of manipulating the mode of exercise; the influence of exercise intensity and exercise duration; the potential benefits of high intensity interval training (HIIT); and the relative effects of the aforementioned on groups of different ages and at different levels of impaired SI. Other innovative strategies that have received recent attention include assessing whether the impact of exercise on SI is affected by whether it is undertaken in a fed or fasted state, and whether a short exercise bout (exercise snack) performed before meals is beneficial.

The purpose of this review is to provide an overview of the topic for those new to it and an update of recent developments for the established researcher.

\section{METHODS}

A literature search was undertaken using PubMed in November 2015, using search terms 'Exercise' OR 'Physical activity', AND 'Insulin sensitivity'. This resulted in 10185 articles, which were then limited to clinical trials ( $n=1672$ articles), filtered using the terms 'Human' and limited to English language publications $(n=1371)$. Reviews and key articles published in English since 2000 were used to present established knowledge and set the background context, while to identify recent updates the search was reduced to articles published after 2012: this resulted in 394 articles. The abstracts of these articles were then evaluated and studies included if the main focus was an exercise intervention or cross-sectional study of PA habits and not confounded by the inclusion of other interventions, such as drugs or diseases such as cancer. Studies were excluded if SI or other measures of glycaemic control were not included as an outcome measure. Titles were manually sorted and articles rejected if primary objectives were not exercise-based. They were then divided on the basis of whether they assessed the acute responses that occur during or immediately after a bout of PA, or the chronic adaptations that occur over a more prolonged period of time due to repeated exercise bouts-the training effects. A further search using the same search criteria was undertaken in July 2016 when the manuscript was undergoing minor revisions. This identified a further 80 articles that met the criteria of the search terms and the aforementioned manual sorting produced the resultant total of 53 recent articles which are summarised in tables $1-3$. tables 1 and 3 .

In presenting this review, the authors acknowledge the growing evidence for the adverse effects of sedentary behaviour on diabetes risk and SI, and that this aspect of behaviour needs to be considered in the wider context of metabolic health. Likewise that exercise may benefit the SI of patients with a number of chronic disease conditions, such as cancers, but due to word limits, these scenarios were beyond the scope of this review.

\section{Molecular mechanisms for exercise-induced changes in SI and glycaemic control}

Glucose uptake into skeletal muscle occurs via facilitated diffusion down the diffusion gradient through the presence of the glucose transporter GLUT4 in the sarcolemma and $\mathrm{T}$ tubules. A single bout of exercise promotes acute increases in glucose uptake into the skeletal muscle, both during the exercise bout and for some hours postexercise. This increase occurs as a result of GLUT4 being translocated from intracellular sites to the sarcolemma and $\mathrm{T}$ tubules, thereby increasing the sites at which glucose can diffuse into the muscle. For a detailed review of the processes resulting in increased glucose uptake during exercise, readers are directed to that by Richter and Hargreaves. ${ }^{10}$

In summary, during a bout of exercise the increased contraction-stimulated glucose uptake is linked to increases in AMP-activated protein kinase (AMPK), which results in the phosphorylation of the RabGTPase-activating protein TBC1D $1 .{ }^{11}$ This phosphorylation appears to inactivate the TBC1D1, although there is some suggestion that the TBC1D1 needs to be phosphorylated at both the AMPK and Akt sites for deactivation to occur. ${ }^{12}$ Since active TBC1D1 has an inhibitory effect, its deactivation enables GTP to react with Rab proteins on the GLUT4 vesicles, and as a consequence there is an increase in GLUT4 vesicle translocation and glucose uptake into the cell.

It appears that a slightly different pathway is used to regulate glucose uptake at rest, and involves TBC1D4 (also known as AS160), the paralogue of TBC1D1. TBC1D4 is involved in the insulin stimulated regulation of GLUT4 translocation and glucose uptake in adipocytes and myocytes. Insulin promotes the phosphorylation of TBC1D4 causing its deactivation and thereby increasing GLUT4 activity. TBC1D4 is also involved in the regulation of glucose uptake postexercise, when increases in SI are associated with elevated intracellular kinase Akt, which results in the phosphorylation of TBC1D4. ${ }^{11}$ TBC1D4 has similar properties to TBC1D1 and produces similar effects, in that the active form TBC1D4 promotes the hydrolysis of GTP to GDP on Rab proteins, thereby preventing the translocation of GLUT4 to the cell membrane. Whereas 


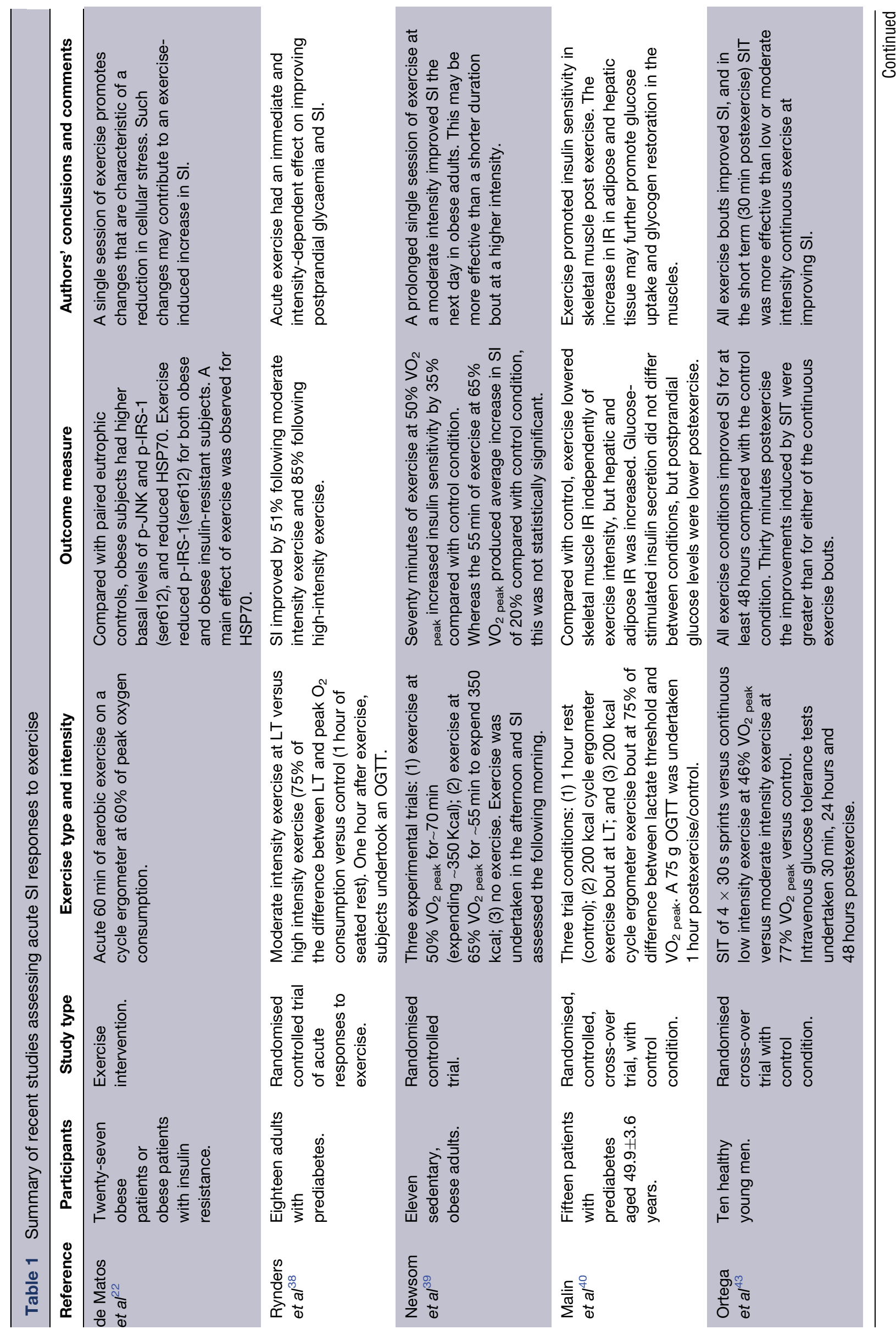




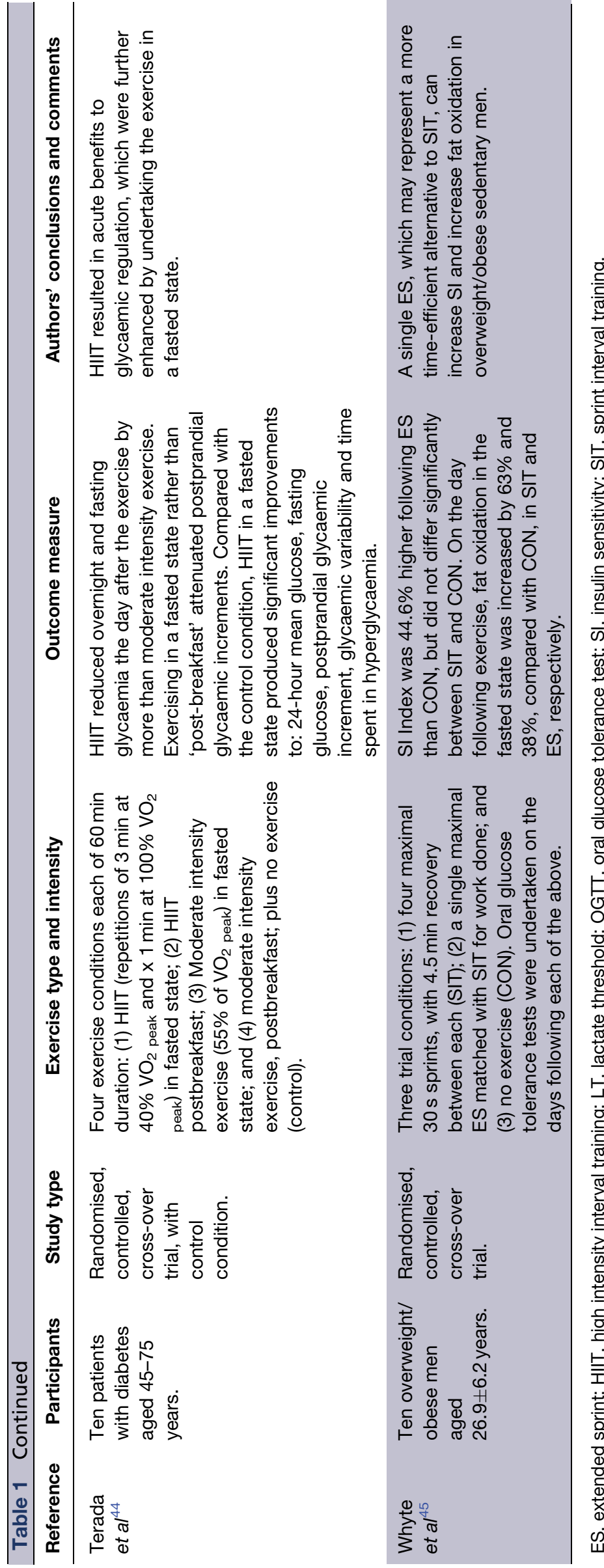


when TCB1D4 is phosphorylated and deactivated the GTP reaction with Rab proteins increase GLUT4 translocation to the cell membrane and $\mathrm{T}$ tubules, which elevates SI. ${ }^{13}$ However, in contrast with TCB1D1, TCB1D4 appears to display a delayed response to exercise/contraction stimuli, with its deactivation exerting an effect postexercise rather than during exercise, ${ }^{11}$ an effect which has also been reported in rats. ${ }^{14}$ Regular exercise training may also result in chronic improvements in TBC1D4 phosphorylation and thereby increase basal SI. ${ }^{11}$

Repeated exercise bouts (exercise-training) have been demonstrated to increases GLUT4 concentrations in populations with metabolic syndrome (MetS) and $\mathrm{T} 2 \mathrm{D},{ }^{15}$ and these increases are associated with changes in SI. ${ }^{6} 16 \quad{ }^{17}$ Such improvements are tissue specific, as exercise appears to improve skeletal muscle but not hepatic SI, nor insulin-stimulated glucose uptake in adipose tissue. ${ }^{18} 19$ In addition to this, the improvements are primarily located in the muscle fibres undertaking most of the work during the exercise. ${ }^{20}$

Other molecules associated with the SI regulatory processes include insulin receptor substrate 1 (IRS-1) and IRS-2. While the precise roles of these receptor molecules require further elucidation, it is evident that they are activated by the insulin receptor tyrosine kinase and promote the phosphorylation/activation of Akt, ${ }^{21}$ thereby promoting glucose uptake into the cell. Reduced p-IRS-1 (ser ${ }^{612}$ ) phosphorylation has been reported in obese and obese insulin-resistant subjects, suggesting an association between lower concentrations of activated IRS-1 and impaired SI, whereas acute increases in IRS-1 phosphorylation have been demonstrated following a single $60 \mathrm{~min}$ bout of moderate intensity exercise $\left(60 \% \mathrm{VO}_{2}\right.$ peak $)$, suggesting an association with increased activation of IRS-1 and improved SI. ${ }^{22}$

\section{Obesity, excess lipid availability and SI}

It is well established that obesity and an associated excess of available lipids results in a loss of SI in skeletal muscle, and this may be linked with impaired deactivation of TCB1D4. ${ }^{23}$ Paradoxically, while obesity increases intramyocellular triglyceride (IMTG) concentrations, so does endurance exercise training. ${ }^{24}$ Yet the skeletal muscles of obese sedentary individuals have a compromised SI, while those of well trained endurance athletes are highly insulin sensitive. ${ }^{24}{ }^{25}$ Hence there must be a distinct molecular basis, other than differences in IMTG concentration to explain their contrasting SI characteristics. Diacylglycerols (DAGs) and ceramides are lipid intermediates that have been proposed to explain this apparent paradox. However, while some studies have demonstrated that exercise can reduce DAGs in previously inactive obese individuals, with a concomitant increase in $\mathrm{SI},{ }^{25}{ }^{26}$ the causative role of DAGs has been questioned as the muscles of endurance trained athletes have been shown to have nearly twice the DAG content of obese sedentary individuals and have a 50\% higher DAG content than normal-weight sedentary individuals. ${ }^{27} 28$

Conversely, evidence is accumulating for the view that ceramides (sphingolipid metabolites) may be the causal link between saturated fatty acid content (but not unsaturated fats) in skeletal muscle and impaired SI. ${ }^{27-29}$ In the acute phase, exercise has been demonstrated to increase serum ceramide, ${ }^{30}$ but these returned to basal levels 2 hours postexercise, while the sphingolipids lipids measured in this study were not elevated during exercise but declined to below basal levels postexercise. However, exercise training has been demonstrated to reduce plasma ceramides and these changes are negatively correlated with increased SI. ${ }^{31}$ An explanation for the molecular link between ceramides and SI is through the presence of excess saturated FFA. ${ }^{29}$ This explanation suggests that the excess saturated FFA and associated high ceramide content inhibits Akt/PKB phosphorylation and activation by protein phosphatase $2 \mathrm{~A}$, thereby preventing the translocation of Akt/PKB from the cytoplasm to the membrane. This may then link to the aforementioned effects on the activation of other signalling molecules, leading to an impaired translocation of GLUT4 to the membrane.

Other molecular and physiological changes linked to exercise induced improvements to SI

Other molecules that may be linked to aerobic exercise induced changes in SI include intracellular adhesion molecule $1, \mathrm{C}$ reactive protein and serum amyloid $\mathrm{A}$, all of which have been shown to be associated with impaired SI, but are reduced by exercise and weight loss, thereby suggesting a link with vascular inflammation. $^{22}$ Additionally, exercise stimulated increases in glycogen synthase activity have also been proposed as a factor that increases SI. ${ }^{23}$

Another process through which SI may be improved is through the exercise training stimulated increase in skeletal muscle capillarisation. Prior et $a l^{32} 33$ reported that increases in capillarisation correlated with improvements in insulin sensitivity following 6 months of aerobic exercise with weight loss in older adults with impaired glucose tolerance (IGT). This outcome was further investigated when after 6 months of training the participants followed a 2-week no aerobic exercise washout phase, in order to isolate the acute postexercise changes in SI from the training effects. The outcome of this was that while many of the aforementioned molecular factors returned to baseline after the washout, capillary density and SI remained elevated by $15 \%$ and $18 \%$, respectively, providing evidence for a link between these two factors. ${ }^{34}$

Additionally, while a good level of cardiorespiratory fitness (CRF) is associated with a reduced risk of poor insulin sensitivity, exercise interventions don't always find an association between improvements in SI and 
$\mathrm{CRF}\left(\mathrm{VO}_{2}\right.$ max $)$. This may be because improvements in CRF are a result of a combination of both peripheral adaptations within the muscle and central cardiovascular adaptations, such as increases in cardiac output, the latter of which may not impact on SI directly. ${ }^{35}$

An alternative mechanism by which exercise could improve glycaemic control, is via the enhancement of pancreatic $\beta$ cell activity, which can become compromised as a consequence of overstimulation and excessive insulin secretion in response to a loss of SI. In support of this, it has been reported that exercise training plus weight loss can increase pancreatic $\beta$ cell function in a linear dose-response manner in adults with prediabetes. ${ }^{34}$ In this study, relatively high exercise doses of $>1900 \mathrm{kcal} /$ week were used and the exercise intensity increased from $60 \%-65 \% \mathrm{HR}_{\max }$ during the first 4 weeks, to a relatively high $80 \%-$ $85 \% \mathrm{HR}_{\max }$ for the following 8 weeks. Hence the intervention was of relatively high volume and intensity, which may not be feasible for most of the population in question. By comparison, Madsen et $a l^{36}$ reported improved $\beta$ cell function in patients with T2D following more moderate volumes of exercise training in the form of high intensity interval training (HIIT, hence the exercise intensity may be key. However, Slentz et $a l^{37}$ have suggested that while both moderate and vigorous exercise are capable of stimulating improvements in $\beta$ cell function as indicated by the Disposition Index (DI $=$ SI $\mathrm{x}$ acute insulin response to glucose (AIRg)), they may do so via different mechanisms, since in their 8-month intervention study, large volumes of moderate intensity exercise produced a greater DI improvement than vigorous exercise, and achieved this with an improvement in SI but virtually no change in AIRg, while the vigorous exercise improved SI and resulted in a compensatory reduction in AIRg.

\section{Updates to acute SI responses to exercise}

Studies assessing the acute responses during or immediately following a single bout of aerobic exercise suggest that SI is improved by more than $50 \%$ for up to 72 hours after the last exercise bout. ${ }^{6}$ However, this acute improvement in SI is lost within 5 days after the last exercise bout, even in highly trained subjects. ${ }^{6}$

Table 1 summarises recent studies that assessed acute responses to exercise on SI. Rynders et al's study confirms the previously reported improvements in SI in patients with prediabetes of around 50\% 1 hour after aerobic exercise. ${ }^{38}$ Likewise, Newsom et al reported an increase in SI in sedentary obese adults the day after moderate intensity exercise ${ }^{39}$ indicating that the acute response was evident for some hours. However, whereas Rynders et $a l^{38}$ reported higher intensity exercise to produce greater improvements in SI $(85 \%$ following high intensity exercise vs $51 \%$ following moderate intensity exercise), Newsom et $a l^{39}$ found that it did not. Indeed Newson et al reported that their lower intensity $\left(50 \% \mathrm{VO}_{2}\right.$ peak $)$ but longer duration bout of the same calorific cost was more effective as it resulted in a statistically significant $35 \%$ improvement in $\mathrm{SI}$, whereas their bout at $65 \% \mathrm{VO}_{2}$ peak only resulted in a $20 \%$ increase that was not statistically significant. The discrepancy between these studies may at least in part be due to the differences in the 'higher' exercise intensities used in these studies, with Newsom et al's being of a more 'moderate' rather than 'high' intensity.

In a more recent study, Malin et $a l^{40}$ sought to identify the acute impact of exercise intensity on different components of insulin sensitivity and indicators of glycaemic control, including: glucose-stimulated insulin secretion (GSIS), skeletal muscle IR ( $\left.\mathrm{SM}_{\mathrm{IR}}\right)$, hepatic IR $\left(\mathrm{HOMA}_{\mathrm{IR}}\right)$ and adipose IR (ADIPOSE $\left.\mathrm{IR}\right)$. In their study they administered a $75 \mathrm{~g}$ OGTT 1 hour postexercise/ control and in their analyses they assessed the relationship between the aforementioned measures and reported that exercise lowered $\mathrm{SM}_{\mathrm{IR}}$ independently of exercise intensity, but that compared with controls, high intensity exercise $(200 \mathrm{kcal}$ cycle ergometer exercise bout at $75 \%$ of difference between lactate threshold and $\mathrm{VO}_{2}$ peak) increased $\mathrm{HOMA}_{\mathrm{IR}}$ and ADIPOSE $_{I R}$ : which may initially appear contradictory. However, since GSIS was not reduced postexercise and the DIs of the hepatic and adipose tissues were lowered with high intensity exercise, while that of muscle increased, it resulted in a lower postprandial blood glucose. Based on these findings the authors suggest that insulin secretion from the pancreas matches the combined requirements of these tissues and there is some communication between them to produce this outcome. They also suggest that the elevated HOMA IR and ADIPOSE $_{I R}$ may be beneficial postexercise, as it could promote greater glucose uptake into the skeletal muscle, in which IR is lower, and thereby more effectively promote the restoration of muscle glycogen postexercise.

The variable of exercise intensity is manipulated and taken to greater extremes through the prescription of 'high-intensity interval training' or sprint interval training (SIT), in which relatively short bursts of high intensity exercise are interspersed with lower intensity activity or rest recovery. ${ }^{41}$ Gibala $e t a l^{42}$ propose that the term HIIT be used when repeated short bouts of exercise at intensities of between $80 \% \mathrm{HR}_{\max }$ and $100 \% \mathrm{HR}_{\max }$ are used, while protocols that involve repeated short bouts of maximal 'all-out' exercise at intensities greater than the work rate that elicits $\mathrm{VO}_{2}$ max be classified as SIT.

In the context of studies assessing the impact of short duration, high intensity exercise, including HIIT and SIT, Ortega $e a^{43}$ found that while their high intensity intervals (four $30 \mathrm{~s}$ sprints), continuous low intensity $\left(46 \% \mathrm{VO}_{2}\right.$ peak $)$ and moderate intensity $\left(77 \% \mathrm{VO}_{2}\right.$ peak $)$ exercise bouts all improved insulin sensitivity in healthy men for at least 48 hours, the repeated sprints 
produced the greatest short-term effects $30 \mathrm{~min}$ postexercise. Similarly, the study by Terada $e t a l^{44}$ reported that $60 \mathrm{~min}$ of HIIT (repetitions of $3 \mathrm{~min}$ at $40 \% \mathrm{VO}_{2}$ peak and $1 \mathrm{~min}$ at $100 \% \mathrm{VO}_{2}$ peak), reduced overnight and fasting glycaemia the day after the exercise by more than a bout of continuous moderate intensity exercise at $55 \%$ of $\mathrm{VO}_{2}$ peak. They also reported that exercising in a fasted state rather than 'post-breakfast' attenuated postprandial glycaemic increments; and compared with the control condition, HIIT in a fasted state produced significant improvements to: 24 hour mean glucose, fasting glucose, postprandial glycaemic increment, glycaemic variability and time spent in hyperglycaemia.

In comparison, Whyte et al compared four maximal $30 \mathrm{~s}$ sprints with $4.5 \mathrm{~min}$ recovery between each (SIT) and a single maximal extended sprint matched for work done. ${ }^{45}$ The day following exercise, the SIT session had failed to improve SI over a control (no exercise) condition, but the extended sprint had improved SI by $45 \%$. Hence the failure of SIT to improve SI in this study contradicts the findings of Ortega et $a l^{43}$ but raises the possibility of a single bout of high intensity exercise of relatively short duration (approximately $2-3 \mathrm{~min}$ ) being sufficient stimulus to promote the regulatory processes underlying improvements in SI, and this requires further elucidation.

\section{Updates on the association between SI and PA-lifestyle studies}

Table 2 summarises the results from recent studies assessing potential links between a lifestyle involving regular PA and SI. Uemura et al's ${ }^{46}$ survey confirms previous work that demonstrates a link between a lifestyle involving PA and better glycaemic control, as did Rosenberger et $a l^{47}$ who reported that a lifestyle involving regular walking and other activities reduced by $50 \%$ the OR for MetS. Similarly, Caro et $a l^{48}$ reported a significantly lower (21 vs $46 \%$ ) prevalence of MetS in people who complied with the aerobic exercise guidelines of $30-60 \mathrm{~min}$ of moderate activity 5 days per week.

The importance of lifestyle is evident even in young people as a survey of children found that PA was negatively associated with markers of IR, ${ }^{49}$ and the study by Telford et al found that the prevalence of IR was reduced in primary school age children when PA was increased in school. ${ }^{50}$

\section{Updates from studies assessing the effects of exercise training upon SI}

Exercise training studies generally report health benefits for the majority of participants, providing the exercise dose is of an appropriate intensity, frequency, duration and is undertaken for sufficient time. ${ }^{7} 20$ Meta-analyses and reviews indicate that regular aerobic exercise that complies with exercise prescription guidelines, ${ }^{51}$ increases SI by $\sim 25-50 \% .{ }^{6} 8$ This training adaptation is likely induced by the increased activity of the muscle fibres, since low intensity aerobic activity, which primarily uses type 1 fibres, induces changes in type 1 fibres expressing myosin heavy chain (MHC) I, but not type 2 fibres (expressing MHC IIA or MHC IIX) ${ }^{12}$ If such adaptations are specific to the fibres that experience increased activity, then this presents the possibility of higher intensity exercise, which involves a greater recruitment of the type 2 fibres, inducing beneficial adaptations in both type 1 and type 2 fibres.

\section{Aerobic exercise interventions, including the assessment of the influence of exercise volume and intensity}

Table 3 summarises the results of recent studies assessing the effect of exercise interventions on SI. Studies consistently show that moderate aerobic exercise for $30 \mathrm{~min}$ or more, three or more times a week for 8 weeks or more improves SI and other markers of glycaemic control. This has been reported in a range of populations including women with diabetes, ${ }^{52} \mathrm{men}$ and women with diabetes and IGT $^{53} 54$ obese men, ${ }^{55}$ obese women, ${ }^{56}$ obese and overweight postmenopausal women, ${ }^{38}$ obese adolescents, ${ }^{57}{ }^{58}$ obese patients, ${ }^{59}$ sedentary moderately overweight young men, ${ }^{19} 60$ subjects with MetS, ${ }^{61}$ older obese adults with IGT, ${ }^{34}$ obese adolescent girls, ${ }^{62}$ and adults with T2DM and non-alcoholic fatty liver disease. ${ }^{63}$

A commonly advocated exercise prescription of three sessions per week of 30 min walking was used by Motahari-Tabari et $a l^{64}$ who reported improvements in the homoeostatic model assessment of insulin resistance (HOMA-IR), fasting plasma insulin and fasting glucose in women with T2D, following 8 weeks of this aerobic exercise regimen. Likewise, Herzig et $a l^{65}$ found that 60 min of walking, three times a week for 3 months in patients with prediabetes improved HOMA-IR, fasting and 2-hour insulin, despite no improvements in fasting 2-hour glucose or $\mathrm{VO}_{2}$ max. The finding of an improvement in SI without an improvement in $\mathrm{VO}_{2}$ max concurs with some previously mentioned studies. ${ }^{37}$

Damirchi et $a l^{66}$ also demonstrated an improvement in insulin sensitivity in middle-aged men with MetS following a 6-week aerobic exercise programme of three sessions per week of 25-40 min walking or running at $50-60 \% \mathrm{VO}_{2}$ peak, and also reported the interesting finding that this benefit was lost within 6 weeks of detraining. Solomon et al reported improvements in glucose-stimulated insulin secretion, but not SI in participants with T2D or IGT, ${ }^{67}$ and suggested that training-induced changes in $\beta$ cell function may be a key determinant of training-induced improvements in glycaemic control. Additionally, Skleryk et al did not find any beneficial changes from 5 days a week of aerobic exercise at $65 \% \mathrm{VO}_{2}$ peak in overweight/obese sedentary men, ${ }^{55}$ but their exercise intervention was only for 2 weeks and may not have been of sufficient duration to induce detectable changes. Likewise, 


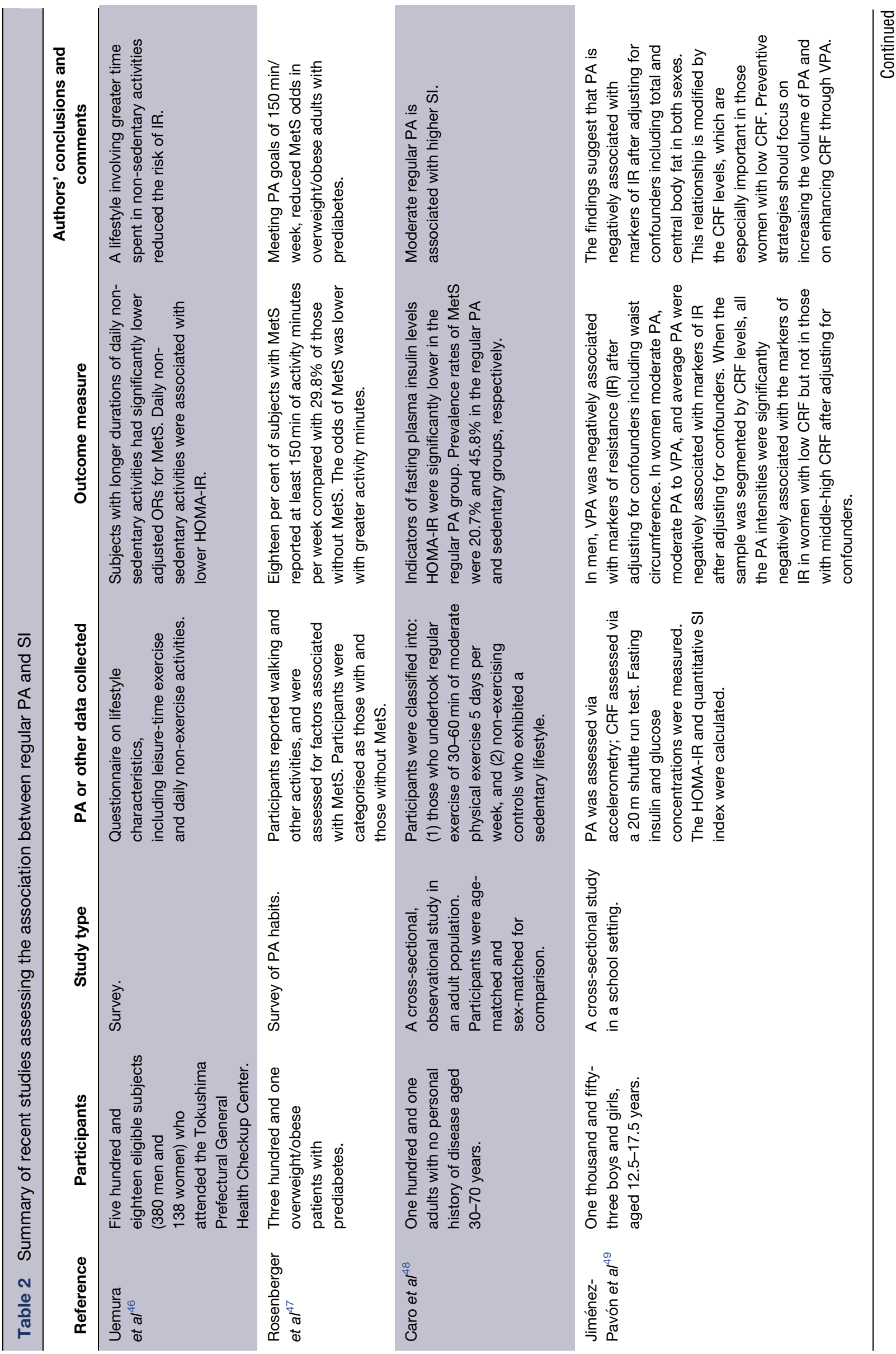



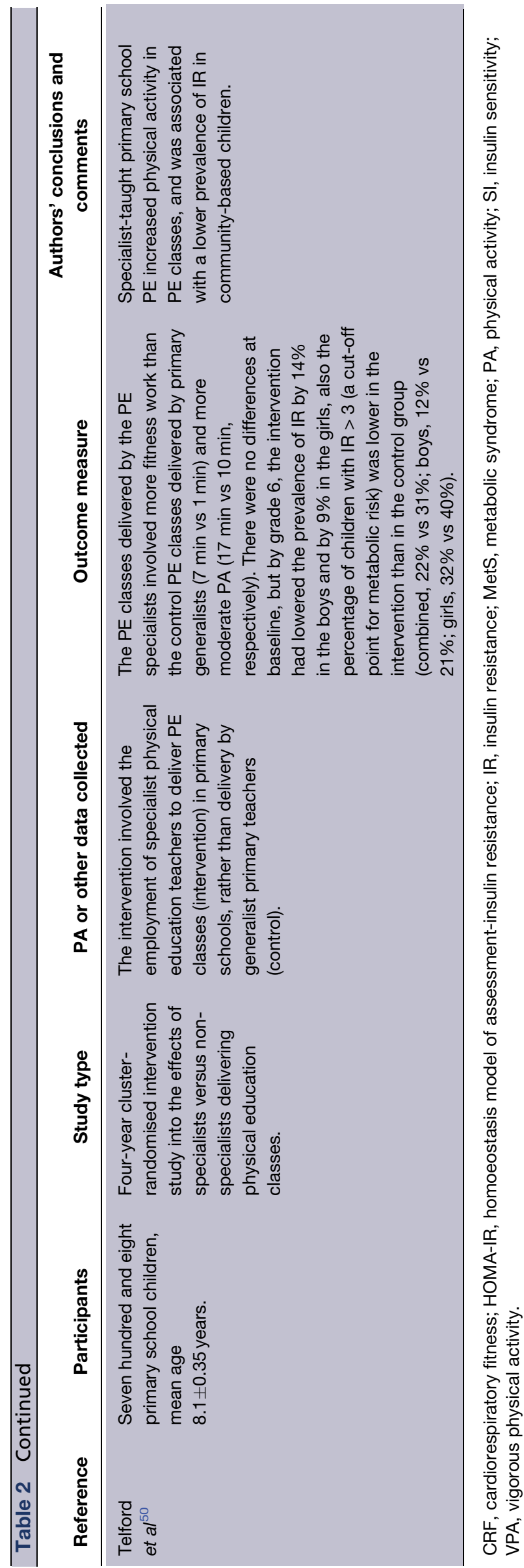


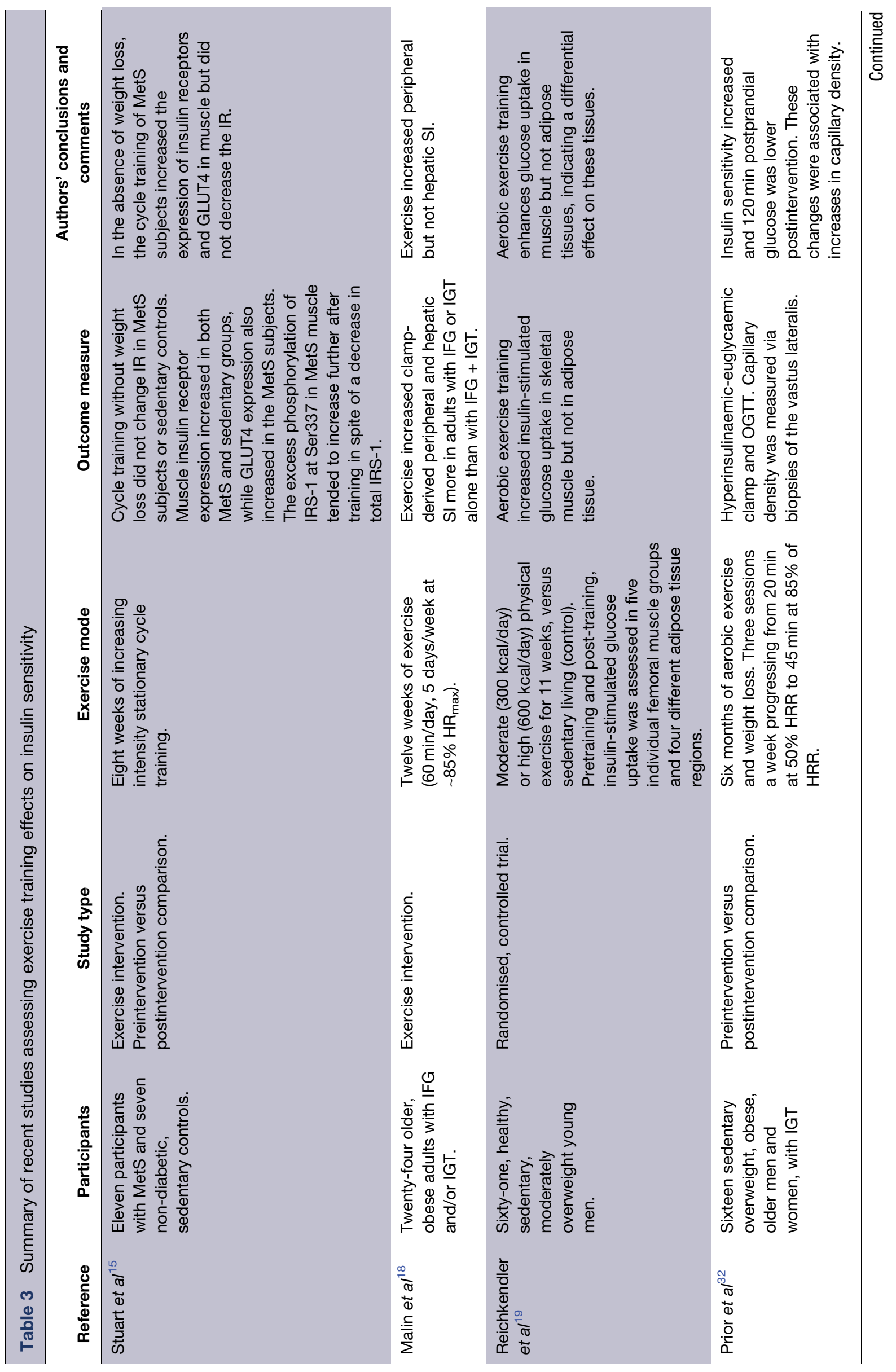

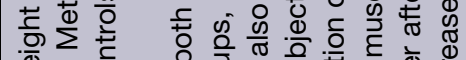
.

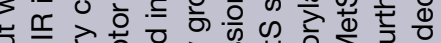

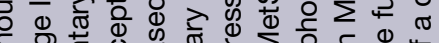
ᄃ

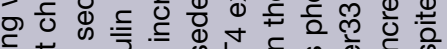

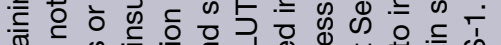
믕 类

要 齐 을 종 $\frac{\pi}{0} \frac{0}{0}$

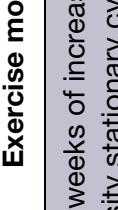

更

我

离

要

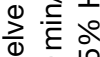

$3 \stackrel{\infty}{\infty}$

Ф)

员 §

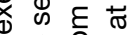

类

F.

更

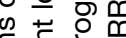

要

x 을 3 


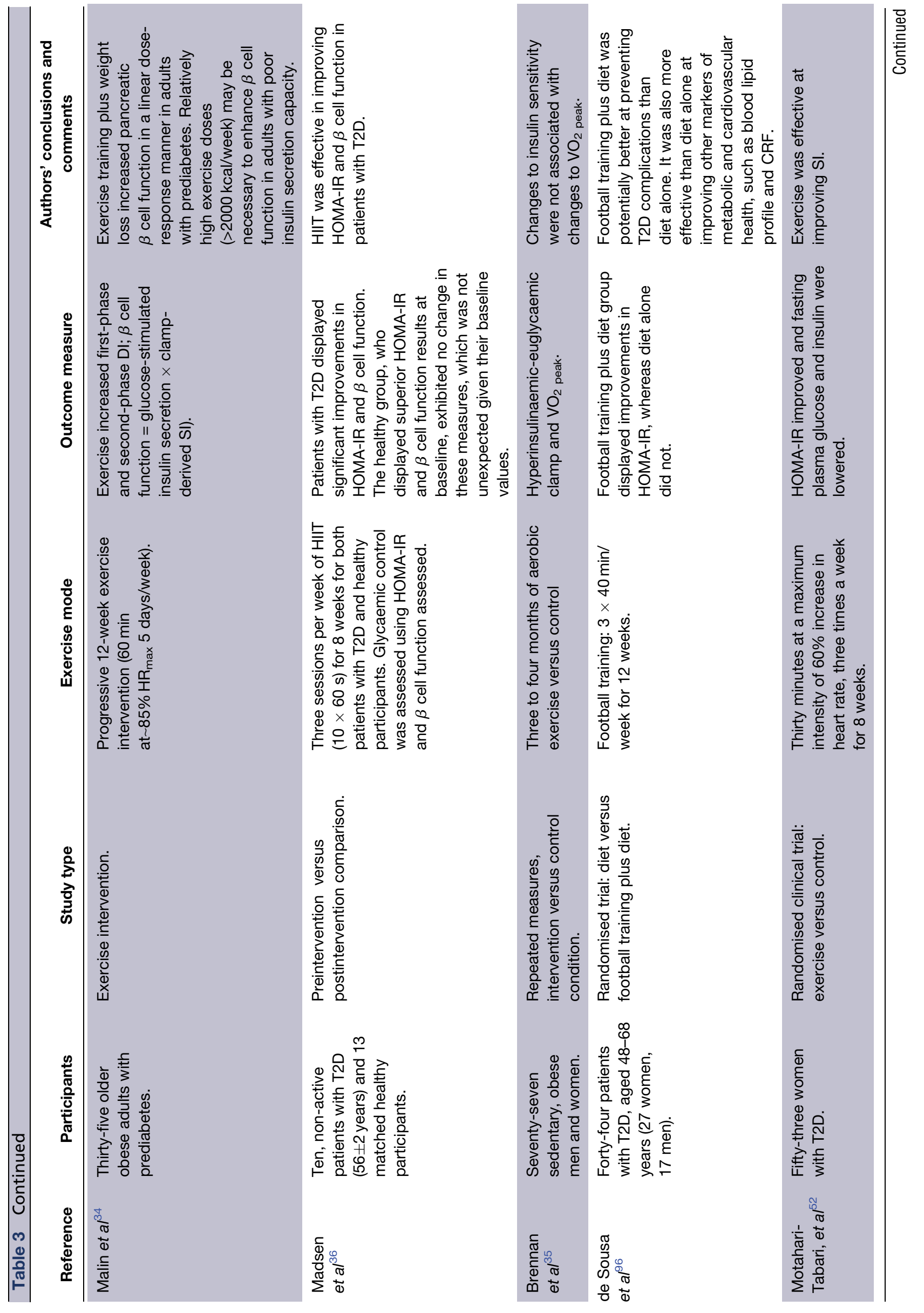




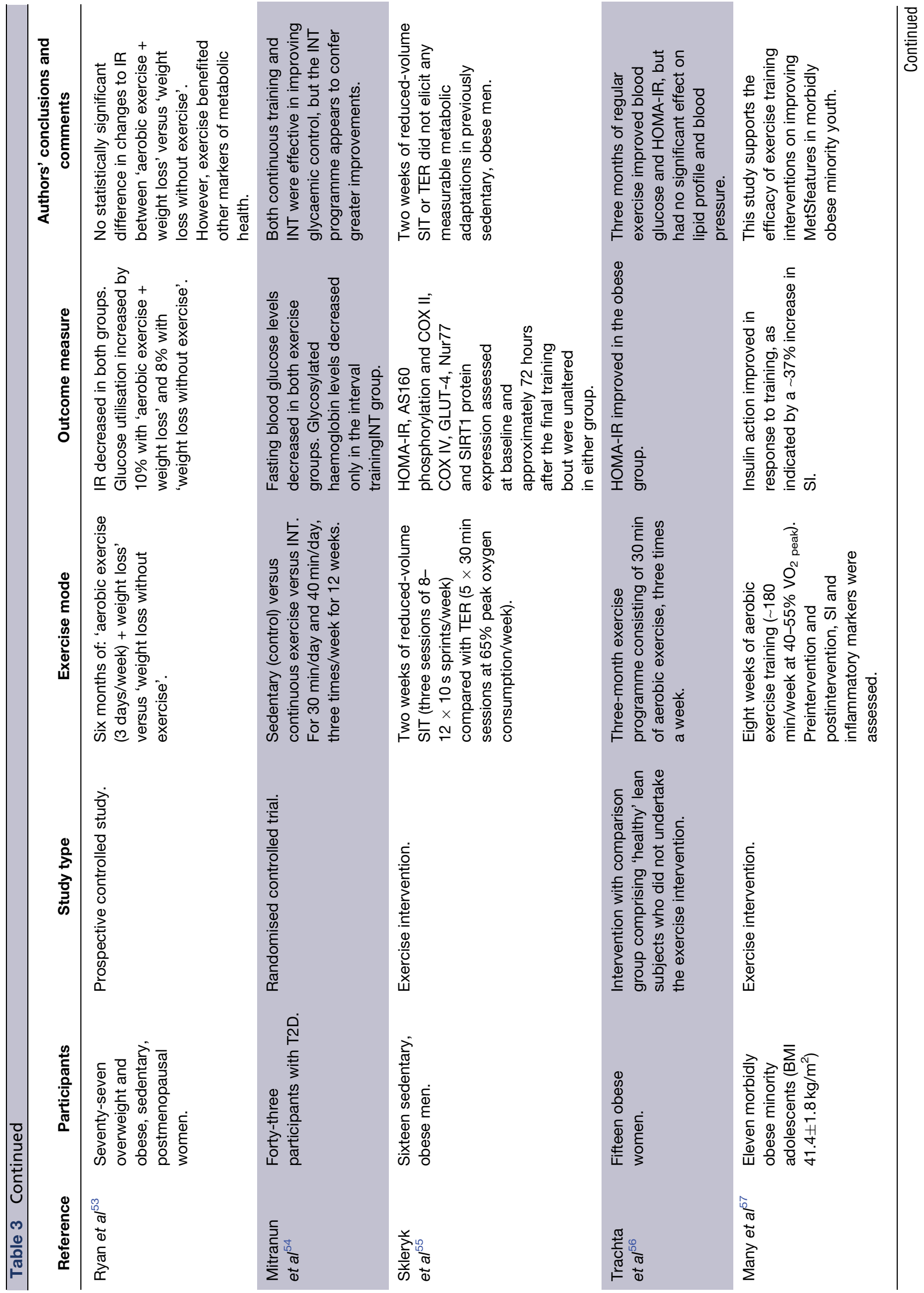




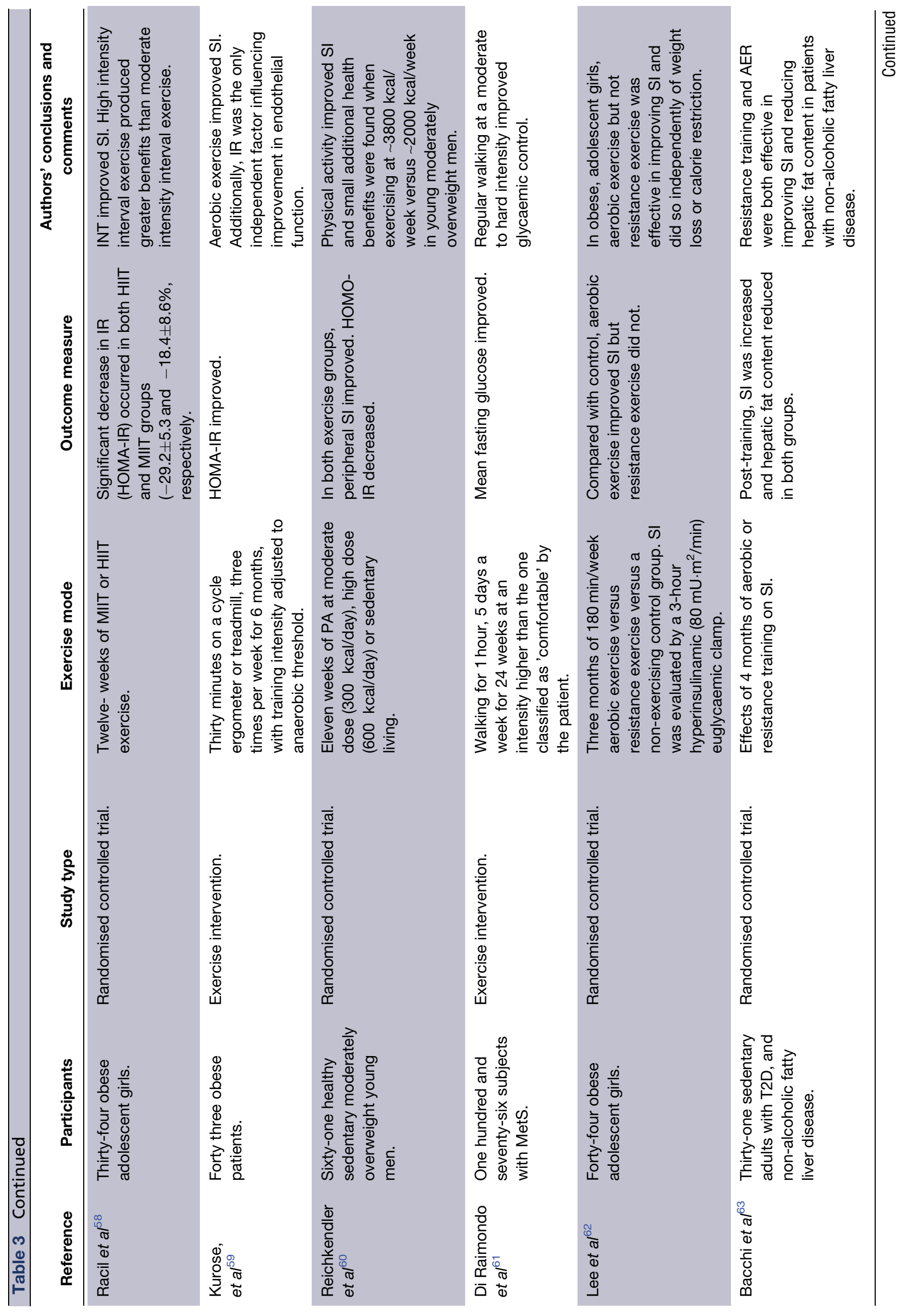




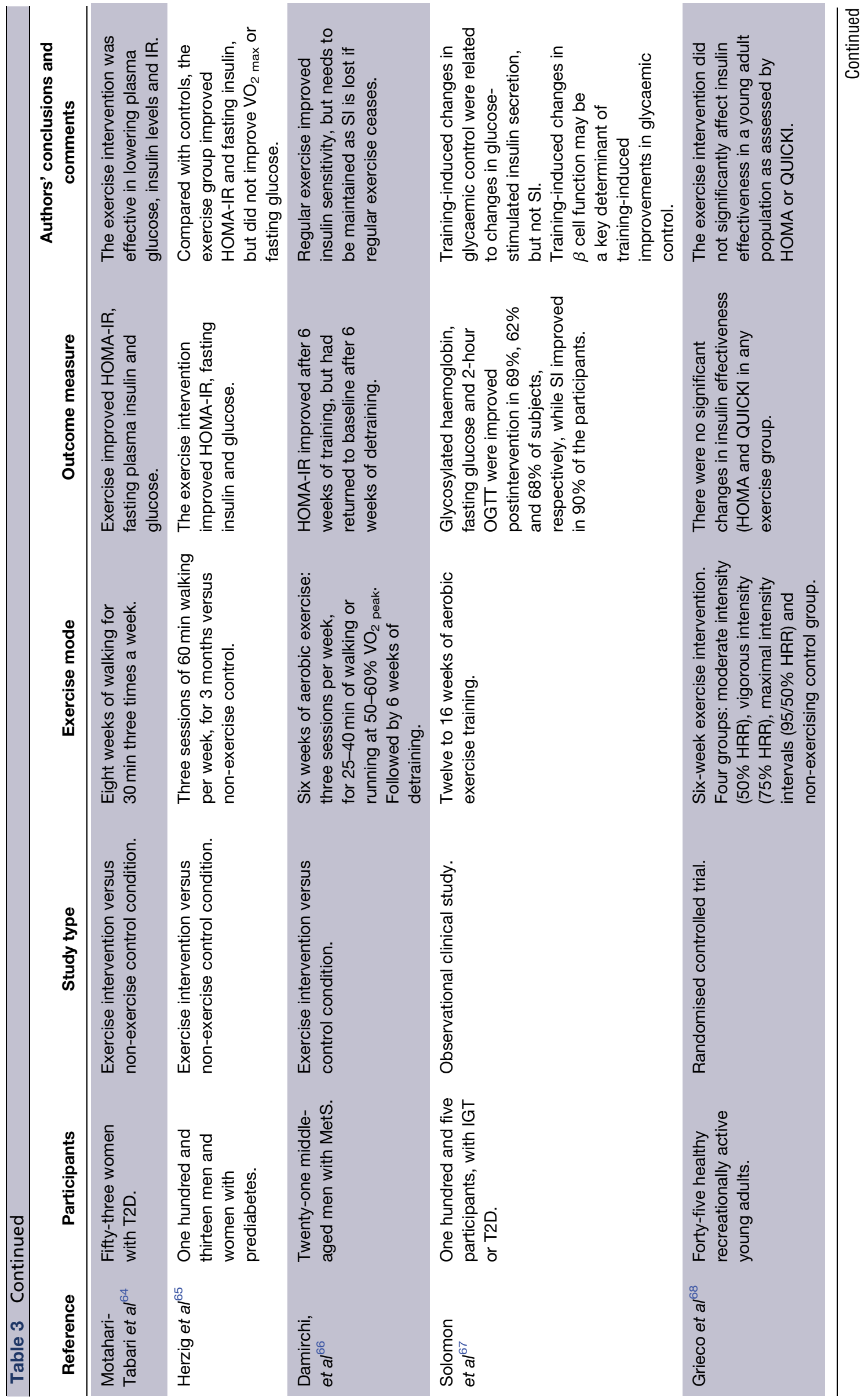




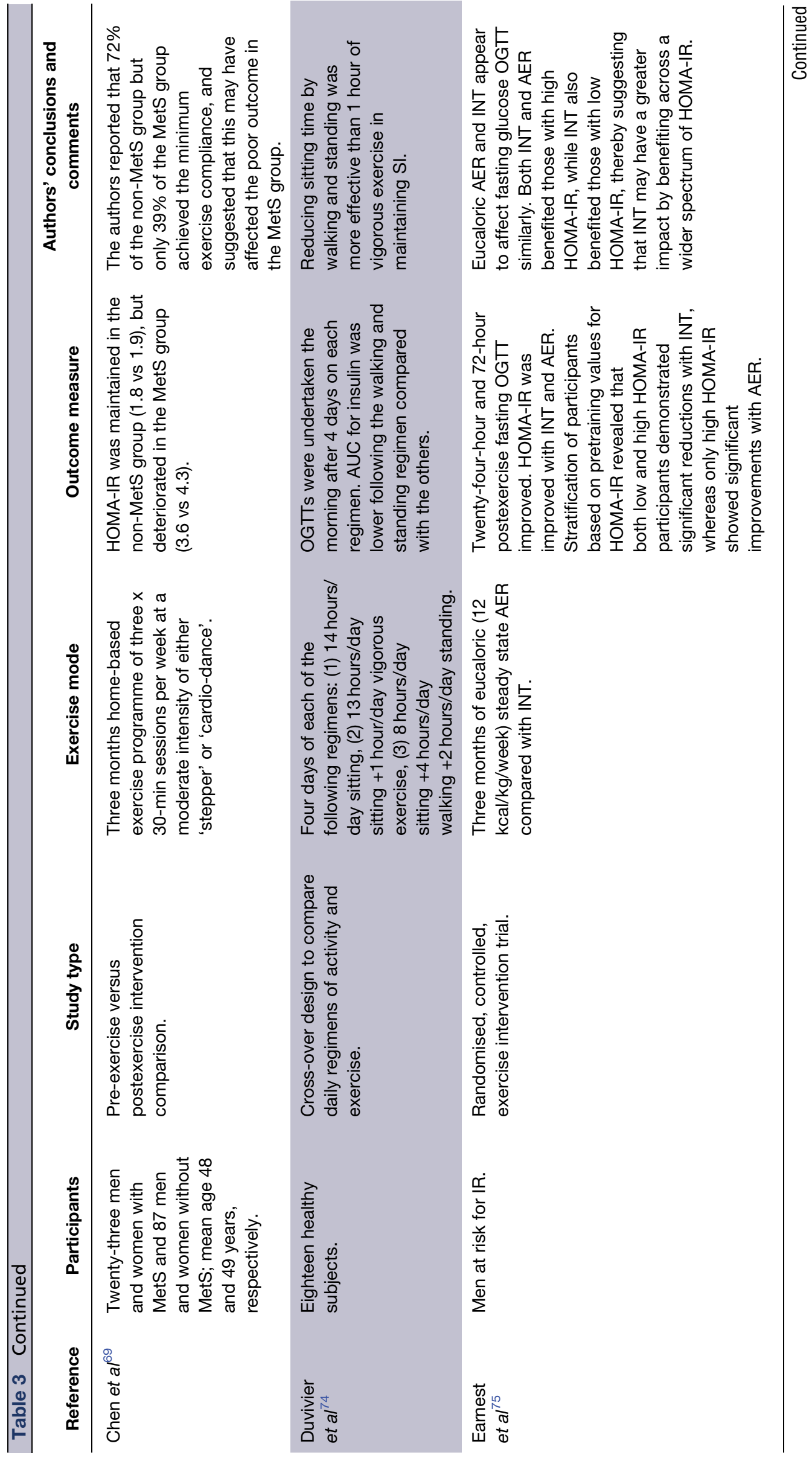




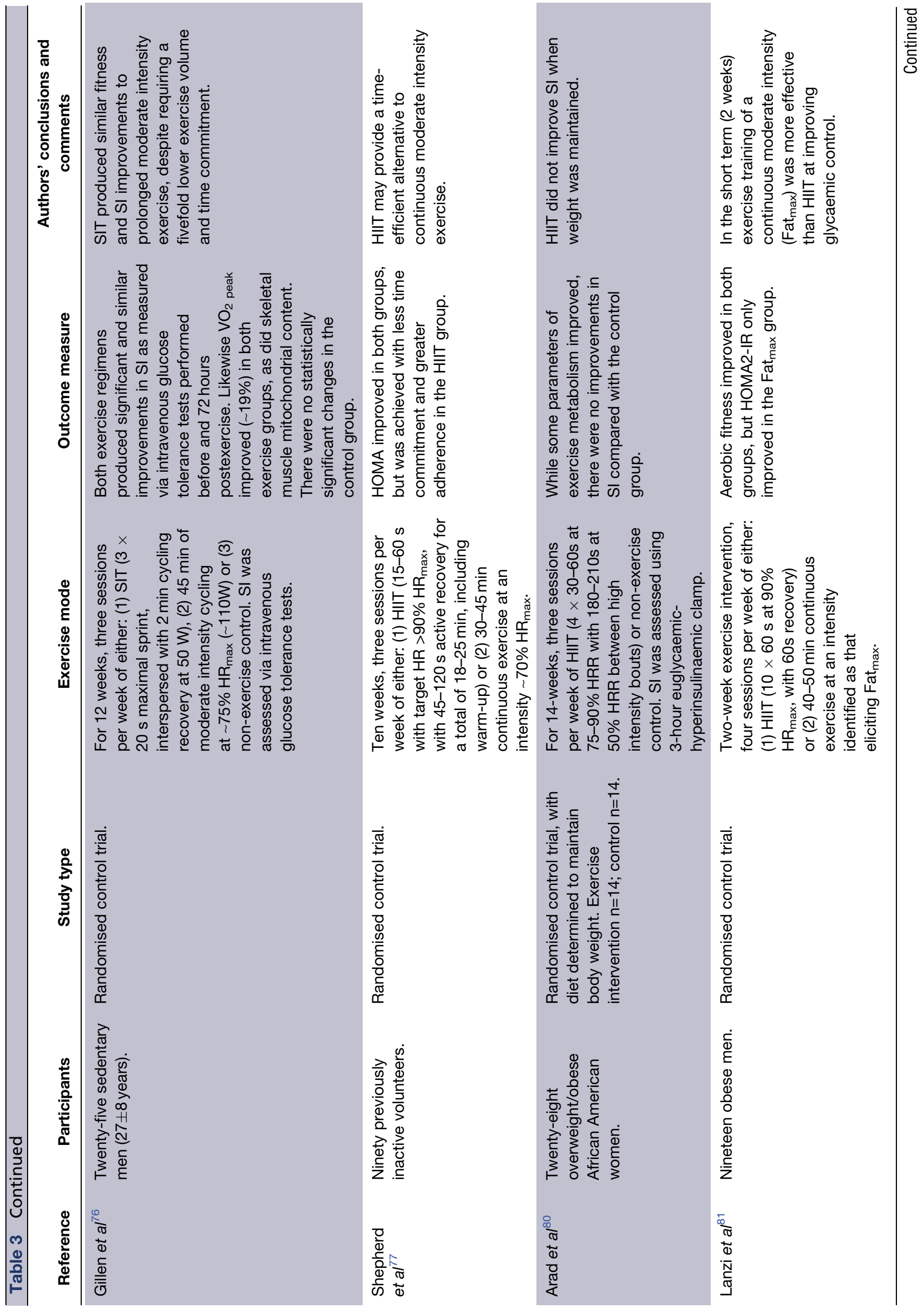




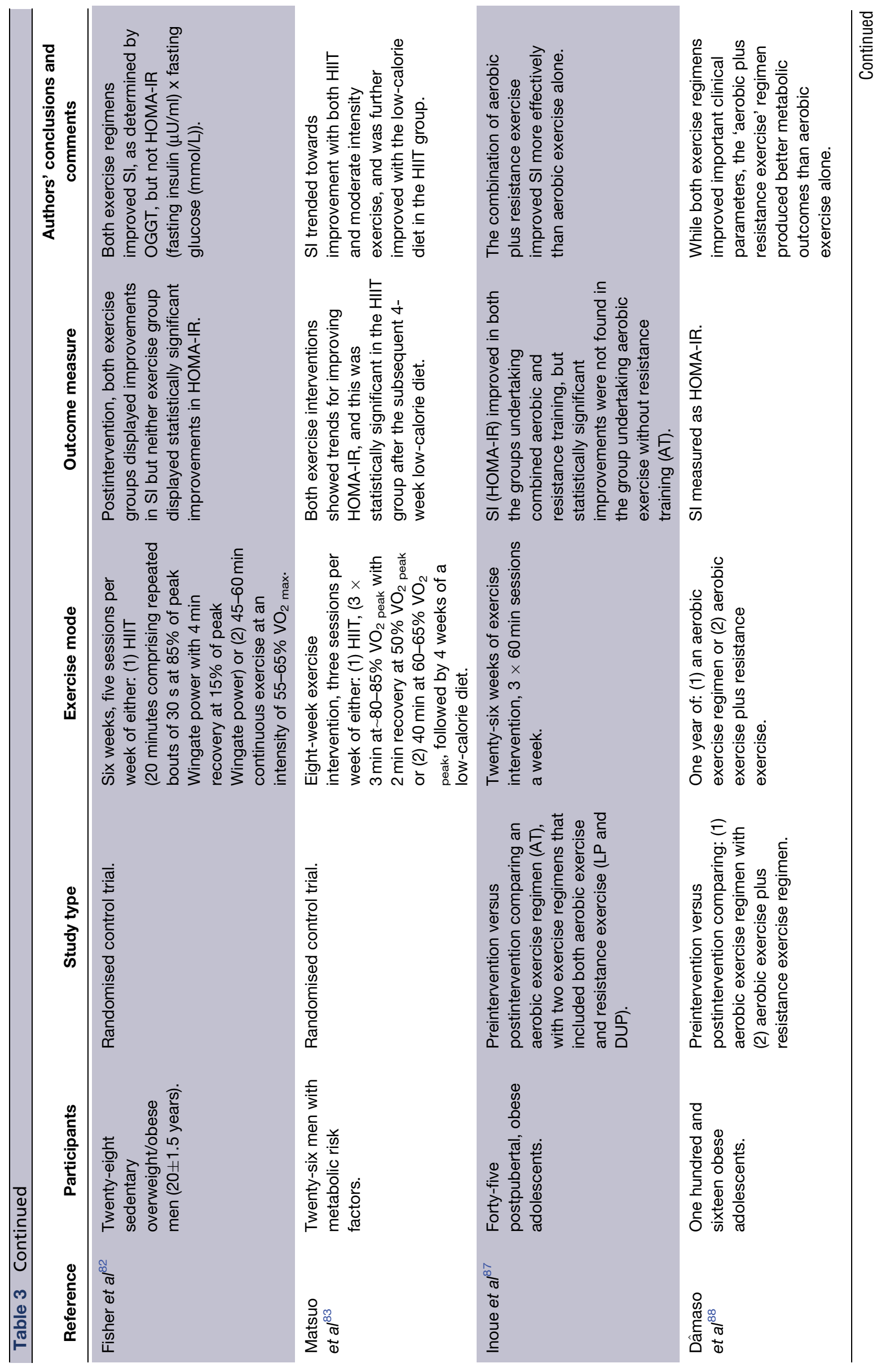

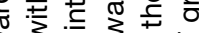
芒选 $\Phi$

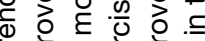

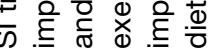

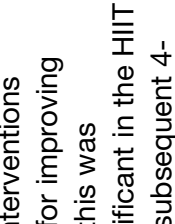
눈 d

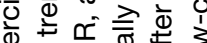

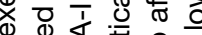

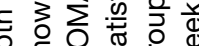




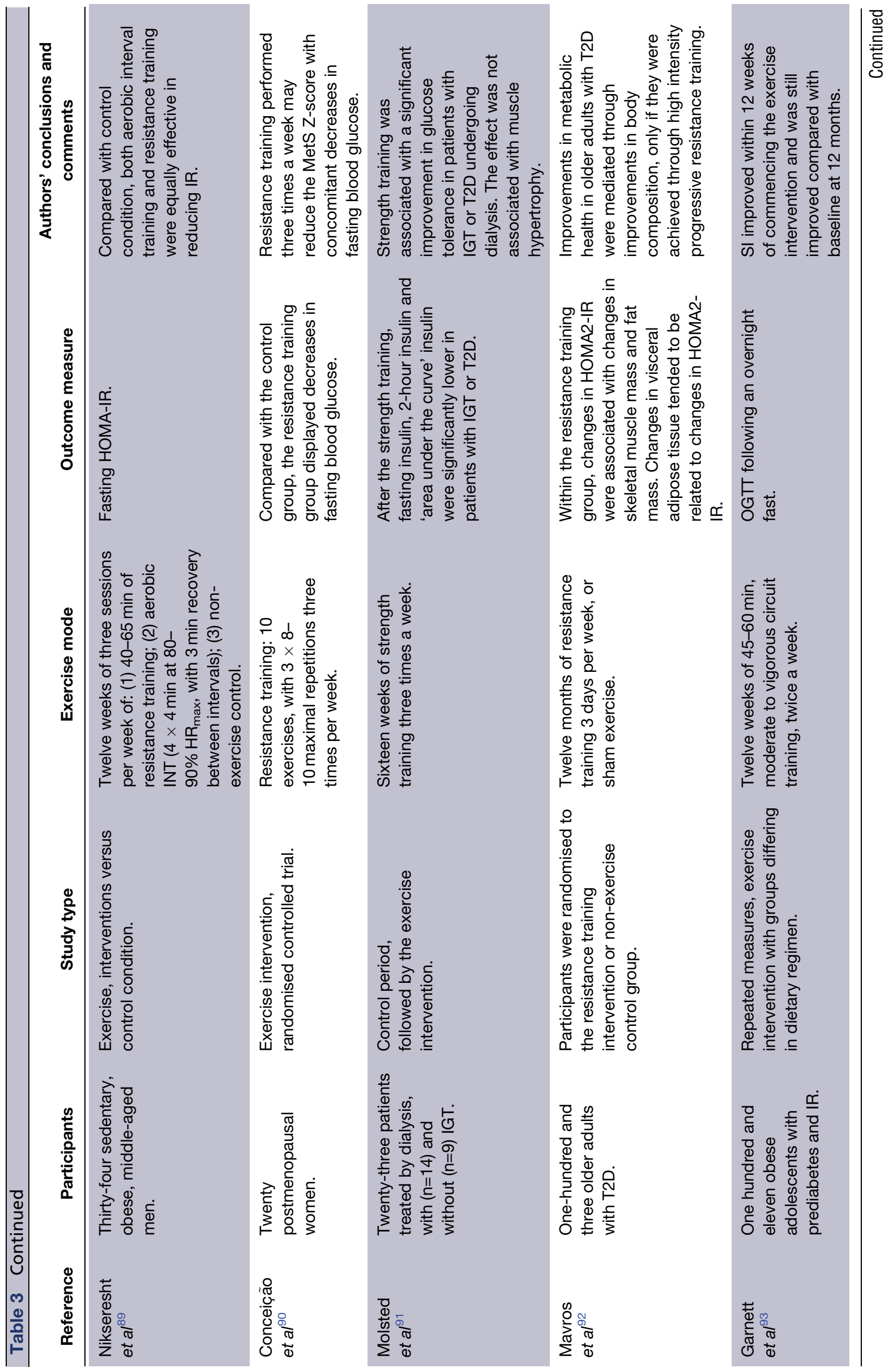


Grieco et al's study on recreationally active young adults did not change insulin effectiveness, ${ }^{68}$ although, given that the participants were already recreationally active it may be that their prestudy values were not sufficiently poor to be changed by the relatively short 6-week intervention.

Chen et al's study also produced results that were not in accordance with similar studies and they suggested that this may have been due to participants' lack of compliance and exercise intensity, ${ }^{69}$ with their nonMetS group attaining greater compliance and thereby maintaining their SI, while their MetS group displayed poorer compliance, which may have contributed to their decline in SI.

One exercise variable that is subject to manipulation in exercise interventions is that of exercise volume, and in general, studies that have examined a possible dose response report additional benefits from higher exercise doses (>1900 kcal/week), with increases in SI and improved $\beta$ cell function in adults with prediabetes. ${ }^{34}$ While such levels of activity may be desirable, compliance is often low even for much lower exercise volumes $^{70-73}$ and for those who are unable to meet these levels it is evident that much of the health benefit is attained from an exercise dose of only $1900 \mathrm{kcal} /$ week or even less, with only minor additional benefits to fitness, body fat and insulin sensitivity when exercising for $600 \mathrm{kcal} /$ day compared with $300 \mathrm{kcal} /$ day. ${ }^{60}$ Indeed the commonly prescribed dose of $5 \times$ $30 \mathrm{~min}$ of moderate intensity exercise/week, which is reported on numerous occasions to be effective, would be around 475-950 kcal/week.

Another exercise variable that is receiving attention in the research is that of exercise intensity, as many of the adaptations that play a role in the exercise-induced increases in SI display a response that is related to the intensity of the activity. For example, while low-intensity training such as walking for $30 \mathrm{~min}, 3-4$ days per week, for 6 months improves markers of glycaemic control (such as 'area under the curve' (AUC) for insulin), a further 6 months of higher intensity exercise (jogging 3-4 days per week for 6 months) elicits substantially greater improvements. ${ }^{6}$ Some reviews suggest that higher intensity exercise $\left(>75 \%\right.$ of $\mathrm{VO}_{2}$ peak $)$ is more efficacious than lower intensity $(<60 \%$ of $\mathrm{VO}_{2}$ peak). ${ }^{6}$ However, these findings are equivocal as others have reported that lower intensity activity, such as prolonged bouts of standing and walking are more effective than vigorous exercise of the equivalent energy expenditure in improving insulin sensitivity as indicated by OGTTs. ${ }^{74}$ Hence in the context of sustained bouts of continuous exercise the issue of the relative importance of exercise volume in terms of duration or total calorific cost of the exercise, versus the intensity of the exercise remains to be resolved.

Interval training (HIIT and SIT) that uses repeated brief bouts of exercise at intensities that are greater than those used in exercise sessions involving a more 
prolonged single continuous exercise bout has been demonstrated to induce significant increases in GLUT4 protein (up to 260\%) and SI (25\%-35\%) $)^{17} 5458$ 75 with the overall outcomes indicating comparable and, in some cases, superior improvements in SI compared with moderate intensity continuous exercise training, ${ }^{76}$ despite it involving substantially less time commitment and reduced total exercise volume. Additionally, Earnest et $a l^{75}$ found INT to benefit patients with low $\mathrm{HOMA}_{\mathrm{IR}}$ as well as patients with high HOMA IR, whereas moderate intensity aerobic exercise only benefited the patients with high $\mathrm{HOMA}_{\mathrm{IR}}$. Hence interval training could be beneficial to both, and for those with relatively mild IR it may be more effective in preventing further decline and/or restoring SI. As an extension of this, it may be speculated that HIIT could be a more effective preventative exercise regimen for asymptomatic healthy individuals. Furthermore, Madsen et $a l^{36}$ reported that HIIT improved both HOMA-IR and $\beta$ cell function in patients with T2D, hence it could be beneficial across the IR spectrum.

Shepherd $e t a l^{77}$ investigated the efficacy of HIIT in a 'gym-setting' with 90 previously inactive volunteers. In this study they reported that both HIIT and moderate intensity exercise improved SI, but HIIT achieved this with less than half the time commitment and greater adherence. Such findings are important given that a 'lack of time' remains the most commonly cited barrier to regular exercise participation. ${ }^{78} 79$ This, combined with reports of greater enjoyment when compared with sessions undertaken at a constant high intensity, is likely to improve compliance, although the higher intensity of the exercise may make it unsuitable for some 'at risk' individuals with cardiovascular issues. However, not all studies have reported HIIT to improve insulin sensitivity, including those of Arad et $a l^{80}$ in which overweight/obese African American women undertook 14 weeks of HIIT (three sessions a week), while maintaining a stable weight and that of Lanzi $e t a l^{81}$ in which moderate intensity exercise was more effective that HIIT in improving HOMA2-IR in obese men, although the exercise intervention for this later study was only 2 weeks. The complexity of the issue is exemplified in the findings of studies such as that of Fisher $e t a l^{82}$ in which both HIIT and moderate intensity exercise improved SI, as determined by an OGGT, but did not improve IR as determined by HOMA-IR (fasting insulin $(\mu \mathrm{U} / \mathrm{ml}) \mathrm{x}$ fasting glucose $(\mathrm{mmol} / \mathrm{L}))$. In another work, while Matsuo et $a l^{83}$ reported beneficial trends in HOMA-IR following HIIT as well as moderate intensity exercise, the results only reached statistical significance when the participants went on to follow a 4-week low-calorie diet.

\section{Effects of resistance training upon SI}

While much of the early research into exercise and SI has focused on aerobic exercise, recent exercise interventions using resistance training (REX) have demonstrated that this mode of exercise can also improve indicators of glycaemic control in a variety of populations, including older overweight individuals with prediabetes ${ }^{84}$ and postmenopausal women. ${ }^{85}$ However, the training adaptations may not always change all indicators of glycaemic control as Eikenberg et $a l^{84}$ found that twice weekly resistance training for 12 weeks improved 2-hour OGTT results in their participants who commenced the study with IGT and impaired fasting glucose (IFG), but not in those who commenced with IFG without IGT. Likewise, REX did not alter fasting glucose concentrations, AUC or ISI.

At a molecular level, REX consisting of two to three sessions per week for 8-26 weeks, can increase GLUT 4 concentrations and translocation by $30-70 \%$, and enhance SI by $10-48 \%{ }^{6}{ }^{17} 86$ Some studies suggest that these improvements could be partially dependent on the training stimulus increasing muscle mass, as well as qualitative changes within the muscle ${ }^{86}$ with the metabolic adaptations potentially involving changes in the type 2A fibres that are likely to be recruited during REX, as well as type 1 fibres. As indicated elsewhere these adaptations may not be homogenic between fibre types or exercise modalities. Furthermore, since both endurance exercise and REX increase SI, it is possible that a combination of these two training modalities could have additive benefits, ${ }^{16}$ particularly if the molecular targets of these activities differ. Indeed the study by Inoue $e t$ al found that the combination of aerobic plus resistance exercise was better than aerobic exercise alone at improving insulin sensitivity in postpubertal obese adolescents. ${ }^{87}$ These results concur with the findings of Dâmaso $e t a l^{88}$ whose findings also suggested that the combination of aerobic and resistance training had better metabolic outcomes than aerobic training (AER) alone for obese adolescents. Furthermore, Nikseresht $e t a l^{89}$ compared the efficacy of aerobic INT and resistance training and found them to be equally effective in reducing IR and fasting insulin levels, but suggested that the aerobic programme had better anti-inflammatory effects. Consequently the findings of various studies have contributed towards 'evidence-based' exercise recommendations now including both aerobic and REX guidelines for healthy individuals. ${ }^{17}$

A recent study by Conceição et $a l^{90}$ adds further support to the incorporation of REX to improve glycaemic control in postmenopausal women. ${ }^{90}$ However, the influence of changes in muscle mass through resistance exercise requires further elucidation since Molstead et al reported improvements in fasting insulin, 2-hour insulin and the AUC for insulin in patients with IGT or T2D who had no increase in muscle mass ${ }^{91}$ while Mavros et al reported that in their study the improvements in SI (HOMA2-IR) in older patients with T2DM were associated with changes in skeletal muscle mass. ${ }^{92}$ Hence further work is required 
to elucidate the impact of quantitative (mass) and qualitative changes to the skeletal musculature on SI. Bacchi et al in their study on patients with T2DM and nonalcoholic fatty liver disease, found that both REX and aerobic exercise improved SI and reduced hepatic fat content. ${ }^{63}$ Likewise, as previously mentioned, Nikseresht $e t a l^{89}$ found resistance training to be as effective as aerobic INT in reducing IR in obese middle-aged men. Whereas Lee et al did not find REX to improve SI in obese adolescent girls, while aerobic exercise did. ${ }^{62}$

Circuit training is another variation of exercise mode, including elements of resistance training and HIIT, as the exercise sessions typically involve brief bouts of high intensity muscular resistance exercise interspersed with rest periods. Iin studies involving obese 10-17-year-olds with prediabetes, it has been demonstrated to improve SI when undertaken with a dietary intervention. ${ }^{93}$

\section{The effect of exercising in a fed or fasted state and other} exercise-food manipulations

In 2010, Van Proeyen et $a l^{94}$ published a study in which they fed their participants a fat rich $(50 \%$ of $\mathrm{kcal})$ hypercaloric $(\sim+30 \% \mathrm{kcal} /$ day $)$ diet for 6 weeks. During this time the participants exercised (cycling and running) four times a week $(2 \times 60 \mathrm{~min}$ and $2 \times$ $90 \mathrm{~min})$. Some of these participants exercised in a fasted state, while others ate a carbohydrate rich breakfast $\sim 90 \mathrm{~min}$ before the exercise, as well as receiving a carbohydrate drink during the exercise session (CHO-Fed). There was also a non-exercise control group. The overall outcome of this was that the group who trained in a fasted state did not increase their body mass, unlike those in the control and CHOfed groups. The fasted group also displayed superior improvements in SI compared with the control group, whereas the CHO-fed group did not. Furthermore the fasted group showed greater increases in GLUT4, and elevated AMPK $\alpha$ phosphorylation. The conclusions being that exercising in a fasted state may enhance the exercise induced benefits to SI, compared with exercising when carbohydrate had been recently ingested. The enhancements of these training effects appear to concur with the improved acute responses when exercising in a fasted state. ${ }^{44}$ In related work, as mentioned previously, Matsuo et $a l^{83}$ reported that beneficial changes in HOMA-IR were enhanced when the participants underwent a low- calorie diet for 4 weeks following the exercise intervention, even though the exercise intervention had ceased, thus further highlighting the interaction between exercise and diet in influencing SI.

Other exercise-feeding manipulations that have received recent attention include undertaking exercise before meals-'exercise snacks'. ${ }^{95}$ From which, findings indicate that brief bouts of exercise $(6 \times 1 \mathrm{~min}$ incline walking at $\left.90 \% \mathrm{HR}_{\max }\right) 30 \mathrm{~min}$ before main meals improved glycaemic control in individuals with IR.

\section{Exercise, SI and changes to body mass}

Numerous studies have reported that exercise induced improvements in SI are independent of changes to body composition or diet induced weight loss, and that the benefits of exercise and weight loss are additive, ${ }^{56}$ as reported by de Sousa et $a l^{96}$ who found football training coupled with weight loss improved insulin sensitivity and blood lipid profile, whereas weight loss alone did not. However these findings are not unequivocal as some studies report weight loss to be the key component to improving SI, for example, Stuart et al found that AER without weight loss did not improve SI in individuals with MetS, whereas exercise with weight loss did, thereby implying that the main influence on improving SI was weight loss rather than exercise. ${ }^{15}$ Similarly, Trussardi Fayhn et al found that exercise training did not add to the effect that weight loss had on improving SI in obese individuals. ${ }^{97}$

By way of comparison, several recent studies suggest that the combination of exercise training and diet is more effective than diet alone in improving SI, and even when the additional benefits of exercise plus diet versus diet alone were modest, ${ }^{62}{ }^{94}$ the inclusion of exercise improved other markers of metabolic health. ${ }^{53}$ Likewise, Mavros et al reported that improvements in metabolic health in older patients with T2DM were mediated through improvements in body composition only if they were achieved through high intensity progressive REX. ${ }^{93}$

\section{Non-responders and adverse responders to exercise interventions}

While there is unequivocal evidence for PA improving population and participant group mean values, indicating positive changes in the majority of participants within the data, it is evident that there is considerable variation in the magnitude of response to exercise interventions within the population: with some individuals displaying considerably greater changes in a variety of health-related outcome measures than others, despite adhering to the same exercise regimen. ${ }^{98}$ Additionally, the magnitude of change in one factor, such as $\mathrm{VO}_{2}$ peak, is not necessarily associated with the magnitude of change in another factor. For example, in the HART-D study, a 9-month exercise training intervention for patients with T2DM, ${ }^{99}$ $57 \%$ of participants displayed an increase in their peak oxygen uptake $\left(\mathrm{VO}_{2}\right.$ peak $)$, while the remaining $43 \%$ exhibited no change. Of those who did show an improvement, only around two-thirds increased their $\mathrm{VO}_{2}$ peak by $>5 \%$ (high responders to exercise), and a third displayed $<5 \%$ increase (low responders to exercise). Yet despite this disparity in the magnitude of change in aerobic capacity, the exercise intervention 
induced similar improvements in $\mathrm{HbA}_{1 \mathrm{c}}$ and body composition (reduction \% body fat) in both responders and non-responders for $\mathrm{VO}_{2}$ peak. Hence the improvements in glycaemic control were associated with participating in the exercise training, but were not associated with changes to aerobic fitness, expressed as percentage improvement in $\mathrm{VO}_{2}$ peak, which was also a finding of the study by Herzig. ${ }^{65^{2}}$

Furthermore, there is also evidence that a minority of the population may respond adversely to exercise intervention, as reported in the HERITAGE study on 1687 men and women, in which $126(8.4 \%)$ displayed an adverse change (increase $>3.5 \mathrm{mU} / \mathrm{L}$ ) in fasting insulin. ${ }^{100}$ The underlying reasons for these adverse changes are unknown, but their elucidation may further the cause of individualised exercise prescription. ${ }^{100}$

\section{CONCLUSION}

Recently (published 2013-2016) studies involving PA confirm previous research findings of its efficacy in improving SI. A lifestyle incorporating aerobic exercise and/or PA that complies with the guidelines of being of moderate intensity for at least $30 \mathrm{~min}$ on $3-5$ days per week, is associated with improved SI and glycaemic control. Acute improvements in SI (2-72 hours postexercise) occur after a single bout of exercise and chronic adaptations are evident from training studies involving interventions undertaken for at least 8 weeks. The benefits of $\mathrm{PA} /$ exercise are evident across all ages from children to older adults, including those categorised as asymptomatic/healthy, prediabetic/MetS, and patients with T2DM. However, the findings are not unequivocal and even within studies not all indicators of insulin sensitivity and glycaemic control display improvements. Indeed, even with increases in the expression of IRS-1 and GLUT4, decreases in IR are not guaranteed. ${ }^{69} \mathrm{~A}$ dose response is sometimes evident, and exercise sessions using higher intensities, including HIIT and SIT can produce greater benefits to SI, but not always. Indeed there remains the question of whether larger volumes of moderate intensity exercise or lower volumes of higher intensity may produce a different magnitude of adaptation, and could do so via stimulating different adaptations. Researchers are also assessing whether lower volume sessions may have the practical advantages of greater compliance, through increased enjoyment and a lesser time commitment, since lack of time is a commonly given reason for noncompliance with exercise recommendations.

While aerobic exercise interventions usually benefit SI, improvements in SI are not always associated with changes to aerobic fitness $\left(\mathrm{VO}_{2}\right.$ max $)$, for reasons that may be explained by the different adaptations induced by the exercise in the cardiovascular system and peripheral musculature.

REX can improve SI through qualitative changes within the muscle as well as increases in muscle mass but the benefits are not evident in all REX studies. However there is a growing body of evidence for including both aerobic exercise and REX in exercise regimens, as this appears to more effectively improve SI than either mode of exercise alone.

The debate continues over the relative importance of exercise versus weight loss for improving SI and whether the combination of the two is more efficacious for achieving good glycaemic regulation.

The molecular bases for exercise-training induced improvements in SI are linked to increases in GLUT4 concentration and acute exercise-induced increases in Akt that deactivate TCB1D4 increasing GLUT4 translocation to the membrane, an effect that persists for several hours postexercise. Additionally, the increased capillarisation of the skeletal muscle is another factor linked to improved SI. The concentration of ceramides within muscle may provide the casual link between a high concentration of intramuscular saturated fatty acids and impaired SI.

Studies in which improvements to SI were not reported may have been a consequence of their interventions involving exercise intensities that were too low, durations that were too short or a population group whose glycaemic control was relatively good at baseline and/or were already 'recreationally active', and hence the capacity to change was limited.

Acknowledgements The authors thank the reviewers for their helpful and constructive comments that assisted with the finalising of the manuscript.

Contributor SRB undertook the initial search of the published literature and writing of the paper. JAH provided expert specialist input into the molecular sections, the identification of recent reviews that were used to present the established knowledge and contributed to the writing and revisions to the final manuscript.

Competing interests None declared.

Provenance and peer review Not commissioned; externally peer reviewed.

Open Access This is an Open Access article distributed in accordance with the Creative Commons Attribution Non Commercial (CC BY-NC 4.0) license, which permits others to distribute, remix, adapt, build upon this work noncommercially, and license their derivative works on different terms, provided the original work is properly cited and the use is non-commercial. See: http:// creativecommons.org/licenses/by-nc/4.0/

(c) Article author(s) (or their employer(s) unless otherwise stated in the text of the article) 2017. All rights reserved. No commercial use is permitted unless otherwise expressly granted.

\section{REFERENCES}

1. Rosenberger Hale E, Goff DC, Isom S, et al; International Diabetes Federation. IDF atlas. $5^{\text {th }}$ edn. Brussels: International Diabetes Federation, 2011. www.idf.org/diabetesatlas

2. Boyle JP, Thompson TJ, Gregg EW, et al. Projection of the year 2050 burden of diabetes in the US adult population: dynamic modeling of incidence, mortality, and prediabetes prevalence. Popul Health Metr 2010;8:29.

3. DeFronzo RA, Tobin JD, Andres R. Glucose clamp technique: a method for quantifying insulin secretion and resistance. $A m \mathrm{~J}$ Physiol 1979;237:E214-E223.

4. Katz A, Nambi SS, Mather K, et al. Quantitative insulin sensitivity check index: a simple, accurate method for assessing insulin sensitivity in humans. J Clin Endocrinol Metab 2000;85:2402-10. 
5. Berman LJ, Weigensberg MJ, Spruijt-Metz D. Physical activity is related to insulin sensitivity in children and adolescents, independent of adiposity: a review of the literature. Diabetes Metab Res Rev 2012;28:395-408.

6. Roberts CK, Little JP, Thyfault JP. Modification of insulin sensitivity and glycemic control by activity and exercise. Med Sci Sports Exerc 2013;45:1868-77.

7. Hawley JA, Lessard SJ. Exercise training-induced improvements in insulin action. Acta Physiol 2008;192:127-35.

8. Conn VS, Koopman RJ, Ruppar TM, et al. Insulin sensitivity following exercise interventions: systematic review and metaanalysis of outcomes among healthy adults. J Prim Care Community Health 2014;27:211-22.

9. Helmrich SP, Ragland DR, Leung RW, et al. Physical activity and reduced occurrence of non-insulin-dependent diabetes mellitus. $N$ Engl J Med 1991;325:147-52.

10. Richter EA, Hargreaves M. Exercise, GLUT4, and skeletal muscle glucose uptake. Physiol Rev 2013;93:993-1017.

11. Cartee GD. Roles of TBC1D1 and TBC1D4 in insulin- and exercisestimulated glucose transport of skeletal muscle. Diabetologia 2015;58:19-30.

12. Sakamoto K, Holman GD. Emerging role for AS160/TBC1D4 and TBC1D1 in the regulation of GLUT4 traffic. Am J Physiol Endocrino Metab 2008;295:E29-E37.

13. Deshmukh AS, Hawley JA, Zierath JR. Exercise-induced phosphoproteins in skeletal muscle. Int J Obes 2008;32(Suppl 4):S18-S23.

14. Funai K, Schweitzer GG, Sharma N, et al. Increased AS160 phosphorylation, but not TBC1D1 phosphorylation, with increased postexercise insulin sensitivity in rat skeletal muscle. Am J Physiol Endocrinol Metab 2009;297:E242-E251.

15. Stuart CA, South MA, Lee ML, et al. Insulin responsiveness in metabolic syndrome after eight weeks of cycle training. Med Sci Sports Exerc 2013;45:2021-9.

16. Frøsig C, Richter EA. Improved insulin sensitivity after exercise: focus on insulin signaling. Obesity. In Press. 2009;17:S15-S20.

17. Mann S, Beedie C, Balducci S, et al. Changes in insulin sensitivity in response to different modalities of exercise: a review of the evidence. Diabetes Metab Res Rev 2014;30:257-68.

18. Malin SK, Haus JM, Solomon TP, et al. Insulin sensitivity and metabolic flexibility following exercise training among different obese insulin-resistant phenotypes. Am J Physiol Endocrinol Metab 2013;305:E1292-E1298.

19. Reichkendler MH, Auerbach P, Rosenkilde M, et al. Exercise training favors increased insulin-stimulated glucose uptake in skeletal muscle in contrast to adipose tissue: a randomized study using FDG PET imaging. Am J Physiol Endocrinol Metab 2013;305:E496-E506.

20. Daugaard JR, Nielsen JN, Kristiansen S, et al. Fiber type-specific expression of GLUT4 in human skeletal muscle: influence of exercise training. Diabetes 2000;49:1092-5.

21. Guo S. Insulin signaling, resistance, and the metabolic syndrome: insights from mouse models into disease mechanisms. $J$ Endocrinol 2014;220:T1-T23.

22. de Matos MA, Ottone VO, Duarte TC, et al. Exercise reduces cellular stress related to skeletal muscle insulin resistance. Cell Stress Chaperones 2014;19:263-70.

23. Pehmøller C, Brandt N, Birk JB, et al. Exercise alleviates lipidinduced insulin resistance in human skeletal muscle-signaling interaction at the level of TBC1 domain family member 4. Diabetes 2012;61:2743-52.

24. Bruce CR, Anderson MJ, Carey AL, et al. Muscle oxidative capacity is a better predictor of insulin sensitivity than lipid status. $J$ Clin Endocrinol Metab 2003;88:5444-51.

25. Dubé JJ, Amati F, Stefanovic-Racic M, et al. Exercise-induced alterations in Intramyocellular lipids and insulin resistance: the athlete's paradox revisited. Am J Physiol Endocrinol Metab 2008:294:E882-8.

26. Dubé JJ, Amati F, Toledo FGS, et al. Effects of weight loss and exercise on insulin resistance, and intramyocellular triacylglycerol, diacylglycerol and ceramide. Diabetologia 2011;54:1147-56.

27. Amanti F, Dubé JJ, Alvarez-Carnero E, et al. Skeletal muscle triglycerides, diacylglycerols, and ceramides in insulin resistance. Diabetes 2011;60:2588-97.

28. Chavez JA, Knotts TA, Wang LP, et al. A role for ceramide, but not diacylglycerol, in the antagonism of insulin signal transduction by saturated fatty acids. J Biol Chem 2003;278:10297-303.

29. Zierath JR. The path to insulin resistance: paved with ceramides? Cell Metab 2007;5:161-3.

30. Bergman BC, Brozinick JT, Strauss A, et al. Serum sphingolipids: relationships to insulin sensitivity and changes with exercise in humans. Am J Physiol Endocrinol Metab 2015;309:E398-408.
31. Kasumov T, Solomon TP, Hwang C, et al. Improved insulin sensitivity after exercise training is linked to reduced plasma C14:0 ceramide in obesity and type 2 diabetes. Obesity 2015;23:1414-21.

32. Prior SJ, Blumenthal JB, Katzel LI, et al. Increased skeletal muscle capillarization after aerobic exercise training and weight loss improves insulin sensitivity in adults with IGT. Diabetes Care 2014:37:1469-75.

33. Prior SJ, Goldberg AP, Ortmeyer HK, et al. Increased skeletal muscle capillarization independently enhances insulin sensitivity in older adults after exercise training and detraining. Diabetes 2015;64:3386-95.

34. Malin SK, Solomon TP, Blaszczak A, et al. Pancreatic $\beta$-cell function increases in a linear dose-response manner following exercise training in adults with prediabetes. Am J Physiol Endocrinol Metab 2013;305:E1248-54.

35. Brennan AM, Lam M, Stotz $P$, et al. Exercise-induced improvement in insulin sensitivity is not mediated by change in cardiorespiratory fitness. Diabetes Care 2014;37:e95-7.

36. Madsen SM, Thorup AC, Overgaard K, et al. High intensity interval training improves glycaemic control and pancreatic $\beta$ cell function of type 2 diabetes patients. PLoS One 2015;10:e0133286.

37. Slentz CA, Tanner CJ, Bateman LA, et al. Effects of exercise training intensity on pancreatic beta-cell function. Diabetes Care 2009;32:1807-11.

38. Rynders CA, Weltman JY, Jiang B, et al. Effects of exercise intensity on postprandial improvement in glucose disposal and insulin sensitivity in prediabetic adults. J Clin Endocrinol Metab 2014;99:220-8.

39. Newsom SA, Everett AC, Hinko A, et al. A single session of lowintensity exercise is sufficient to enhance insulin sensitivity into the next day in obese adults. Diabetes Care 2013;36:2516-22.

40. Malin SK, Rynders CA, Weltman JY, et al. Exercise intensity modulates Glucose-Stimulated insulin secretion when adjusted for adipose, Liver and Skeletal Muscle Insulin Resistance. PLoS One 2016;11:e0154063.

41. Bird SR, Hawley JA. Exercise and type 2 diabetes: new prescription for an old problem. Maturitas 2012;72:311-6.

42. Gibala MJ, Gillen JB, Percival ME. Physiological and health-related adaptations to low-volume interval training: influences of nutrition and sex. Sports Med 2014;44 Suppl 2:S127-S137.

43. Ortega JF, Fernández-Elías VE, Hamouti N, et al. Higher insulinsensitizing response after sprint interval compared to continuous exercise. Int J Sports Med 2015;36:209-14.

44. Terada T, Wilson BJ, Myette-Cote E, et al. Targeting specific interstitial glycemic parameters with high-intensity interval exercise and fasted-state exercise in type 2 diabetes. Metabolism 2016:65:599-608.

45. Whyte LJ, Ferguson C, Wilson J, et al. Effects of single bout of very high-intensity exercise on metabolic health biomarkers in overweight/obese sedentary men. Metabolism 2013;62:212-9.

46. Uemura $\mathrm{H}$, Katsuura-Kamano $\mathrm{S}$, Yamaguchi $\mathrm{M}$, et al. Abundant daily non-sedentary activity is associated with reduced prevalence of metabolic syndrome and insulin resistance. J Endocrinol Invest 2013;36:1069-75

47. Rosenberger Hale E, Goff DC, Isom S, et al. Relationship of weekly activity minutes to metabolic syndrome in prediabetes: the healthy living partnerships to prevent diabetes. J Phys Act Health 2013;10:690-8

48. Caro J, Navarro I, Romero P, et al. Metabolic effects of regular physical exercise in healthy population. Endocrinol Nutr 2013;60:167-72.

49. Jiménez-Pavón D, Ruiz JR, Ortega FB, et al. HELENA Study group. Physical activity and markers of insulin resistance in adolescents: role of cardiorespiratory fitness levels-the HELENA study. Pediatr Diabetes 2013;14:249-58.

50. Telford RD, Cunningham RB, Telford RM, et al. Physical education can improve insulin resistance: the LOOK randomized cluster trial. Med Sci Sports Exerc 2013;45:1956-64.

51. Colberg SR, Albright AL, Blissmer BJ, et al; American College of Sports Medicine, American Diabetes Association. Exercise and type 2 diabetes: American college of sports medicine and the american diabetes association: joint position statement. exercise and type 2 diabetes. Med Sci Sports Exerc 2010;42:2282-303.

52. Motahari-Tabari N, Ahmad Shirvani M, Shirzad-E-Ahoodashty M, et al. The effect of 8 weeks aerobic exercise on insulin resistance in type 2 diabetes: a randomized clinical trial. Glob $J$ Health Sci 2014:7:115-21.

53. Ryan AS, Ge S, Blumenthal JB, et al. Aerobic exercise and weight loss reduce vascular markers of inflammation and improve insulin sensitivity in obese women. J Am Geriatr Soc 2014;62:607-14. 
54. Mitranun W, Deerochanawong C, Tanaka H, et al. Continuous vs interval training on glycemic control and macro- and microvascular reactivity in type 2 diabetic patients. Scand J Med Sci Sports 2014;24:e69-76.

55. Skleryk JR, Karagounis LG, Hawley JA, et al. Two weeks of reduced-volume sprint interval or traditional exercise training does not improve metabolic functioning in sedentary obese men. Diabetes Obes Metab 2013;15:1146-53.

56. Trachta $\mathrm{P}$, Drápalová J, Kaválková $\mathrm{P}$, et al. Three months of regular aerobic exercise in patients with obesity improve systemic subclinical inflammation without major influence on blood pressure and endocrine production of subcutaneous fat. Physiol Res 2014;63(Suppl 2):S299-308.

57. Many G, Hurtado ME, Tanner C, et al. Moderate-intensity aerobic training program improves insulin sensitivity and inflammatory markers in a pilot study of morbidly obese minority teens. Pediatr Exerc Sci 2013;25:12-26.

58. Racil G, Ben Ounis O, Hammouda O, et al. Effects of high vs. moderate exercise intensity during interval training on lipids and adiponectin levels in obese young females. Eur J Appl Physiol 2013;113:2531-40.

59. Kurose $\mathrm{S}$, Tsutsumi $\mathrm{H}$, Yamanaka $\mathrm{Y}$, et al. Improvement in endothelial function by lifestyle modification focused on exercise training is associated with insulin resistance in obese patients. Obes Res Clin Pract 2014:8:e106-14.

60. Reichkendler MH, Rosenkilde M, Auerbach PL, et al. Only minor additional metabolic health benefits of high as opposed to moderate dose physical exercise in young, moderately overweight men. Obesity 2014;22:1220-32.

61. Di Raimondo D, Tuttolomondo A, Buttà $\mathrm{C}$, et al. Metabolic and anti-inflammatory effects of a home-based programme of aerobic physical exercise. Int J Clin Pract 2013;67:1247-53.

62. Lee $S$, Deldin AR, White D, et al. Aerobic exercise but not resistance exercise reduces intrahepatic lipid content and visceral fat and improves insulin sensitivity in obese adolescent girls: a randomised controlled trial. Am J Physiol Endocrinol Metab 2013;305:E1222-9.

63. Bacchi E, Negri C, Targher G, et al. Both resistance training and aerobic training reduce hepatic fat content in type 2 diabetic subjects with nonalcoholic fatty liver disease (the RAED2 Randomised Trial). Hepatology 2013;58:1287-95.

64. Motahari-Tabari N, Ahmad Shirvani M, Shirzad-E-Ahoodashty M, et al. The effect of 8 weeks aerobic exercise on insulin resistance in type 2 diabetes: a randomised clinical trial. Glob $\mathrm{J} \mathrm{Health} \mathrm{Sci}$ 2015;7:115-21.

65. Herzig KH, Ahola R, Leppäluoto J, et al. Light physical activity determined by a motion sensor decreases insulin resistance, improves lipid homeostasis and reduces visceral fat in high-risk subjects: PreDiabEx study RCT. Int J Obes 2014;38:1089-96.

66. Damirchi A, Tehrani BS, Alamdari KA, et al. Influence of aerobic training and detraining on serum BDNF, insulin resistance, and metabolic risk factors in middle-aged men diagnosed with metabolic syndrome. Clin J Sport Med 2014;24:513-8.

67. Solomon TP, Malin SK, Karstoft K, et al. Pancreatic $\beta$-cell function is a stronger predictor of changes in glycemic control after an aerobic exercise intervention than insulin sensitivity. $J$ Clin Endocrinol Metab 2013;98:4176-86.

68. Grieco CR, Swain DP, Colberg SR, et al. Effect of intensity of aerobic training on insulin sensitivity/resistance in recreationally active adults. J Strength Cond Res 2013;27:2270-6.

69. Chen CN, Chuang LM, Korivi M, et al. Home-based exercise may not decrease the insulin resistance in individuals with metabolic syndrome. J Phys Act Health 2015;12:74-9.

70. Ford ES, Herman WH. Leisure-time physical activity patterns in the U.S. diabetic population: findings from the 1990 national health interview Survey-Health Promotion and Disease Prevention Supplement. Diabetes Care 1995;18:27-33.

71. Troiano RP, Berrigan D, Dodd KW, et al. Physical activity in the United States measured by accelerometer. Med Sci Sports Exerc 2008:40:181-8.

72. Health and Social Care Information Centre. Health survey for England-2008: Physical Activity and Fitness. Leeds, UK: The Information Centre, 2009. http://www.hscic.gov.uk/pubs/hse0 8physicalactivity

73. Colley RC, Garriguet D, Janssen I, et al. Physical activity of canadian children and youth: accelerometer results from the 2007 to 2009 canadian health measures survey. Health Rep 2011;22:15-23

74. Duvivier BM, Schaper NC, Bremers MA, et al. Minimal intensity physical activity (standing and walking) of longer duration improves insulin action and plasma lipids more than shorter periods of moderate to vigorous exercise (cycling) in sedentary subjects when energy expenditure is comparable. PLoS One 2013;8:e55542.

75. Earnest CP, Lupo M, Thibodaux J, et al. Interval training in men at risk for insulin resistance. Int J Sports Med 2013;34:355-63.

76. Gillen JB, Martin BJ, Maclnnis MJ, et al. Twelve weeks of sprint interval training improves indices of cardiometabolic health similar to traditional endurance training despite a Five-Fold lower exercise volume and time commitment. PLoS One 2016;11:e0154075.

77. Shepherd SO, Wilson OJ, Taylor AS, et al. Low-Volume HighIntensity interval training in a gym setting improves CardioMetabolic and psychological health. PLoS One 2015;10:e0139056.

78. Gibala MJ, Little JP, Macdonald MJ, et al. Physiological adaptations to low-volume, high-intensity interval training in health and disease. J Physio/ 2012;590:1077-84.

79. Trost SG, Owen N, Bauman AE, et al. Correlates of adults' participation in physical activity: review and update. Med Sci Sports Exerc 2002;34:1996-2001.

80. Arad AD, DiMenna FJ, Thomas N, et al. High-intensity interval training without weight loss improves exercise but not basal or insulin-induced metabolism in overweight/obese African American women. J Appl Physiol 2015;119:352-62.

81. Lanzi S, Codecasa F, Cornacchia M, et al. Short-term HIIT and fat max training increase aerobic and metabolic fitness in men with class II and III obesity. Obesity 2015;23:1987-94.

82. Fisher G, Brown AW, Bohan Brown MM, et al. High intensity interval- vs Moderate Intensity- Training for Improving Cardiometabolic Health in Overweight or Obese Males: A Randomized Controlled Trial. PLoS One 2015;10:e0138853.

83. Matsuo T, So SN, Shimojo N, et al. Effect of aerobic exercise training followed by a low-calorie diet on metabolic syndrome risk factors in men. Nut Metab Cardiovasc Disease 2015;25:832-8.

84. Eikenberg JD, Savla J, Marinik EL, et al. Prediabetes phenotype influences improvements in glucose homeostasis with resistance training. PLoS One 2016;11:e0148009.

85. Oliveira PF, Gadelha AB, Gauche R, et al. Resistance training improves isokinetic strength and metabolic syndrome-related phenotypes in postmenopausal women. Clin Interv Aging 2015;10:1299-304.

86. Strasser B, Pesta D. Resistance training for diabetes prevention and therapy: experimental findings and molecular mechanisms. Biomed Res Int 2013;2013:805217.

87. Inoue DS, De Mello MT, Foschini D, et al. Linear and undulating periodized strength plus aerobic training promote similar benefits and lead to improvement of insulin resistance on obese adolescents. J Diabetes Complications 2015;29:258-64.

88. Dâmaso AR, da Silveira Campos RM, Caranti DA, et al. Aerobic plus resistance training was more effective in improving the visceral adiposity, metabolic profile and inflammatory markers than aerobic training in obese adolescents. J Sports Sci 2014;32:1435-45.

89. Nikseresht M, Agha-Alinejad H, Azarbayjani MA, et al. Effects of nonlinear resistance and aerobic interval training on cytokines and insulin resistance in sedentary men who are obese. J Strength Cond Res 2014;28:2560-8.

90. Conceição MS, Bonganha V, Vechin FC, et al. Sixteen weeks of resistance training can decrease the risk of metabolic syndrome in healthy postmenopausal women. Clin Interv Aging 2013;8:1221-8.

91. Molsted S, Harrison AP, Eidemak I, et al. Improved glucose tolerance after high-load strength training in patients undergoing dialysis. Nephron Clin Pract 2013;123:134-41.

92. Mavros Y, Kay S, Anderberg KA, et al. Changes in insulin resistance and $\mathrm{HbA} 1 \mathrm{c}$ are related to exercise-mediated changes in body composition in older adults with type 2 diabetes: interim outcomes from the GREAT2DO trial. Diabetes Care 2013;36:2372-9.

93. Garnett SP, Gow M, Ho M, et al. Improved insulin sensitivity and body composition, irrespective of macronutrient intake, after a 12 month intervention in adolescents with pre-diabetes; RESIST a randomised control trial. BMC Pediatr 2014;14:289.

94. Van Proeyen K, Szlufcik K, Nielens H, et al. Training in the fasted state improves glucose tolerance during fat-rich diet. J Physiol 2010;588:4289-302.

95. Francois ME, Baldi JC, Manning PJ, et al. 'Exercise snacks' before meals: a novel strategy to improve glycaemic control in individuals with insulin resistance. Diabetologia 2014:57:1437-45.

96. de Sousa MV, Fukui R, Krustrup P, et al. Positive effects of football on fitness, lipid profile, and insulin resistance in Brazilian patients with type 2 diabetes. Scand J Med Sci Sports 2014;24(Suppl 1):57-65.

97. Trussardi Fayh AP, Lopes AL, Fernandes PR, et al. Impact of weight loss with or without exercise on abdominal fat and insulin 
resistance in obese individuals: a randomised clinical trial. $\mathrm{Br} \mathrm{J}$ Nutr 2013;110:486-92.

98. Winett RA, Davy BM, Savla J, et al. Using response variation to develop more effective, personalized behavioral medicine? evidence from the Resist Diabetes study. Trans/ Behav Med 2014;4:333-8.

99. Pandey A, Swift DL, McGuire DK, et al. Metabolic effects of exercise training among fitness-nonresponsive patients with type 2 diabetes: The HART-D Study. Diabetes Care 2015;38:1494-501.
100. Bouchard C, Blair SN, Church TS, et al. Adverse metabolic response to regular exercise: is it a rare or common occurrence? PLoS One 2012;7:e37887.

101. Lakey WC, Barnard K, Batch BC, et al. Are current clinical trials in diabetes addressing important issues in diabetes care? Diabetologia 2013;56:1226-35. 